\author{
UNIVERSIDADE DE SÃO PAULO \\ FACULDADE DE ECONOMIA, ADMINISTRAÇÃO E CONTABILIDADE \\ DEPARTAMENTO DE ECONOMIA \\ PROGRAMA DE PÓS-GRADUAÇÃO EM ECONOMIA
}

Gabriel Facundes Monteiro

\title{
Migration and Crop Change: Evidence from Brazil using a Spatial Equilibrium Model
}

Migração e Mudança de Cultura Agrícola: Evidência do Brasil usando um Modelo de Equilíbrio Espacial

São Paulo 
Prof. Dr. Vahan Agopyan

Reitor da Universidade de São Paulo

Prof. Dr. Fábio Frezatti

Diretor da Faculdade de Economia, Administração e Contabilidade

Prof. Dr. José Carlos de Souza Santos

Chefe do Departamento de Economia

Prof. Dr. Wilfredo Fernando Leiva Maldonado

Coordenador do Programa de Pós-Graduação em Economia 
Gabriel Facundes Monteiro

\title{
Migration and Crop Change: Evidence from Brazil using a Spatial Equilibrium Model
}

\author{
Migração e Mudança de Cultura Agrícola: Evidência do Brasil usando um Modelo de \\ Equilíbrio Espacial
}

Dissertação apresentada ao Programa de PósGraduação em Economia do Departamento de Economia da Faculdade de Economia, Administração e Contabilidade da Universidade de São Paulo, como requisito parcial para a obtenção do título de Mestre em Ciências.

Orientadora: Paula Carvalho Pereda Versão Corrigida

São Paulo 


\section{Monteiro, Gabriel Facundes}

Migration and Crop Change: Evidence from Brazil using a Spatial Equilibirum Model / Gabriel Facundes Monteiro. - São Paulo, 2021.

$58 p$.

Dissertação (Mestrado) - Universidade de São Paulo, 2021. Orientadora: Paula Carvalho Pereda.

1. Mudanças climáticas. 2. Produtividade agrícola. 3. Troca de culturas agrícolas. 4. Migração interna. 5. Equilíbrio espacial. I. Universidade de São Paulo. Faculdade de Economia, Administração e Contabilidade. II. Título. 


\section{Migration and Crop Change: Evidence from Brazil using a Spatial Equilibrium Model}

Migração e Mudança de Cultura Agrícola: Evidência do Brasil usando um Modelo de Equilíbrio Espacial

Dissertação apresentada ao Programa de PósGraduação em Economia do Departamento de Economia da Faculdade de Economia, Administração e Contabilidade da Universidade de São Paulo, como requisito parcial para a obtenção do título de Mestre em Ciências.

\begin{tabular}{c}
\hline Paula Carvalho Pereda \\
IPE-USP \\
\hline Juliano Junqueira Assunção \\
PUC-Rio \\
\hline Eduardo Amaral Haddad \\
IPE-USP \\
\hline Jaqueline Maria de Oliveira \\
Rhodes College \\
São Paulo \\
2021
\end{tabular}



Ao meu avô,

Raimundo Barros Facundes (in memoriam). 



\section{Acknowledgements}

First of all, I would like to thanks my family - my parents, Jorge and Elenice, and my sister, Mariana - for all the love, support, and patience throughout my life, but specially during these last three years. Regardless of any distance or pandemic, you always provided me the strength and affection I needed.

To my advisor, Professor Paula Pereda, for the guidance, trust, and support. For all moments you helped me find a north in our many online meetings, and for every opportunity you gave me. I cannot state how grateful I am for everything during this journey, and for how much I learned from you.

To Professor Jaqueline Oliveira, whose advice, comments, critiques, and suggestions had key roles in many points of this research. Thank you for all the helpful and fruitful discussions.

To Professors Eduardo Haddad and Ariaster Chimeli, members of the qualifying examination, for the contributions, critiques and suggestions that helped improve this work.

To Professors Maria Dolores Diaz and Fabiana Rocha from BWE - EconomistAs with whom it has been an honor to work with during the recent months. Also, to the whole team from NEREUS for the support in this research.

To all my dear friends who ingressed in this master's degree with me. I could not have hoped for a better group of people to experience with everything we have been through together. A special thanks to José, Leal, and Pedro Salerno for all our coffee breaks and pizza meetings. Also, to João, Camila, Raíssa and Gabriel for the great adventures we had all around São Paulo. To Debora, Pedro Oliveira, Sayon, Lucas, Rodrigo, Rafael and Rafael, Vinícius and, Priscilla for all our moments and conversations inside or outside the salinha.

Finally, I would like to thanks FIPE and CAPES for the financial support in my first year of the master's degree. Also, to Instituto Escolhas for believing in the potential of this project and providing the financial support in my second year. 



\begin{abstract}
Climate-change forecasts for Brazil points to sizable and spatially heterogeneous changes in temperature. This is likely to spur migration and spatial changes in crop patterns. We develop a unique tractable model that integrates both migration and agricultural adaptation as responses to climate change. Our model considers that workers' locational choice is impacted by climate change through three channels: a direct amenity-value channel, as well as the indirect agricultural wages and housing prices channels. The impacts from indirect channels are affected by how farmers adapt to the new climate. Our simulations predict up to an $18.25 \%$ increase in micro-region migration rates, with barely no effect from crop change. On the other hand, agricultural adaptation has important impacts in employment in agriculture. The South macro-region is predicted to have an increase in agriculture share of employment when farmers change crop patterns, this includes a reduction in agriculture area dedicated to the production of Maize and an increase the area dedicated to Coffee in the region. Our results help to identify populations most vulnerable to climate change and the regions where most gains from agricultural adaptation may come from.
\end{abstract}

JEL Classification: Q15, Q54, R13, R14.

Keywords: Climate Change, Agriculture Productivity, Crop Switching, Internal Migration, Spatial Equilibrium 


\section{Resumo}

As previsões de mudanças climáticas para o Brasil apontam para mudanças de temperatura consideráveis e espacialmente heterogêneas. É provável que isso estimule migração e mudanças espaciais nos padrões de cultivo. Desenvolvemos, então, um modelo estimável único que integra migração e adaptação agrícola como respostas às mudanças climáticas. Nosso modelo considera que a escolha da localização dos trabalhadores é impactada pelas mudanças climáticas por meio de três canais: um canal direto de valor-amenidade, bem como os canais indiretos de salários agrícolas e de custos de habitação. Os impactos dos canais indiretos são afetados pela forma como os agricultores se adaptam ao novo clima. Nossas simulações prevêem um aumento de até 18,25\% nas taxas de migração a nível de microrregião, com quase nenhum efeito de mudanças de culturas agrícolas. Por outro lado, a adaptação agrícola tem impactos importantes no emprego na agricultura. Prevê-se que a macrorregião Sul terá um aumento na porção de emprego da agricultura quando os agricultores mudam os padrões de cultivo, o que inclui uma redução na área agrícola dedicada à produção de milho e um aumento na área dedicada ao café na região. Nossos resultados ajudam a identificar as populações mais vulneráveis às mudanças climáticas, assim como as regiões de onde pode vir a maior parte dos ganhos com a adaptação agrícola.

Classificação JEL: Q15, Q54, R13, R14.

Palavras-Chave: Mudanças climáticas, Produtividade agrícola, Troca de culturas agrícolas, Migração interna, Equilíbrio espacial 
Summary

INTRODUCTION .................... 1

2

MODEL ........................ 5

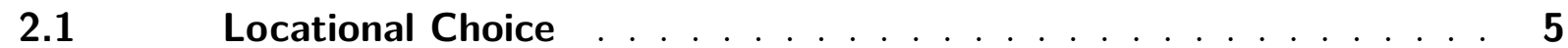

$2.2 \quad$ Agriculture and non-agriculture firms . . . . . . . . . . . 6

$2.2 .1 \quad$ Non-agriculture firm . . . . . . . . . . . . . . 7

$2.2 .2 \quad$ Agriculture Firm . . . . . . . . . . . . . . . . . . . 7

$2.3 \quad$ Land and Housing Market . . . . . . . . . . . . . . . . 9

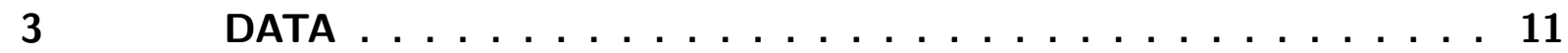

$3.1 \quad$ Agriculture Data . . . . . . . . . . . . . . . . . . 11

3.1.1 Agricultural Census . . . . . . . . . . . . . . . . . 11

3.1.2 Global Agro-Ecological Zones . . . . . . . . . . . . . . . . 12

3.1.3 PAM and Agrostat . . . . . . . . . . . . . . . . . 14

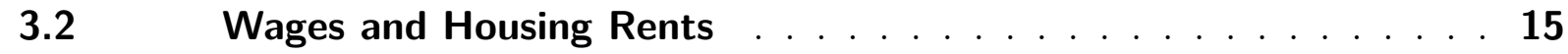

3.3 Weather and Climate Data . . . . . . . . . . . . 16

4 ESTIMATION OF PARAMETERS . . . . . . . . . . . . 18

$4.1 \quad$ Agricultural firm parameters . . . . . . . . . . . . . 18

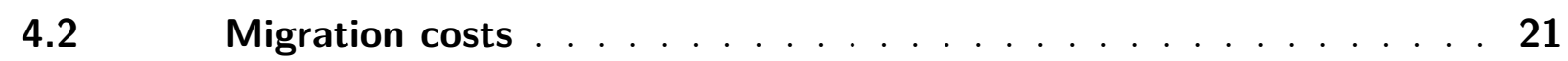

4.3 Decomposing the indirect utility . . . . . . . . . . . . . 23

$4.4 \quad$ Non-agriculture labor demand . . . . . . . . . . . . . . . . . . 23

4.5 Land-Housing market parameters . . . . . . . . . . . . . . 23

4.6 Estimating indirect utility, labor and housing equation . . . . . . . 24

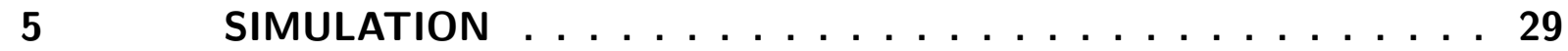

$6 \quad$ RESULTS . . . . . . . . . . . . . . . . . 31

$6.1 \quad$ Changes in Agriculture Production . . . . . . . . . . . 31

6.2 Climate change effects on migration and agriculture . . . . . . . . 34

6.3 Climate change effects on welfare . . . . . . . . . . . 35

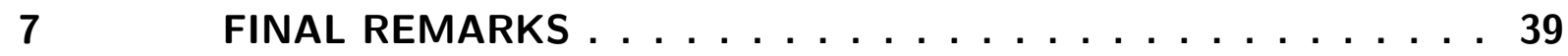

REFERENCE LIST . . . . . . . . . . . . . . . . . . 40

Appendices ....................... . . 43 
Appendix A MODEL ................43

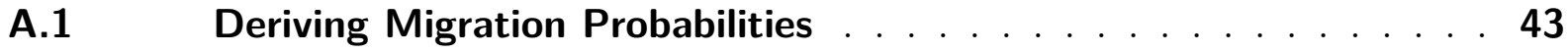

A.2 Workers' Welfare - Expected Utility . . . . . . . . . . . . 44

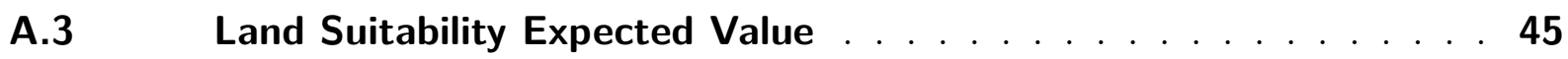

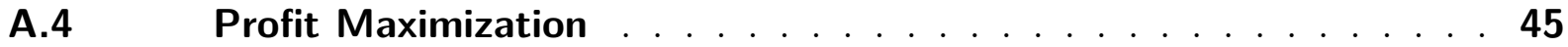

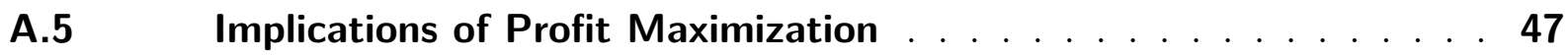

A.6 Conditional Distribution of Land Quality . . . . . . . . . . 49

A.7 Agricultural Wage $\ldots \ldots \ldots \ldots \ldots \ldots$

Appendix B DATA ............... 52

Appendix C ESTIMATION OF THE PARAMETERS . . . . . 54

C.1 Alternative Agriculture Production Model with 10 crops . . . . . . 55 


\section{List of Figures}

Figure 1 - Change in temperature (in degrees Celsius) in summer and winter, B1 and $\mathrm{A} 2$ scenarios . . . . . . . . . . . . . . . 17

Figure 2 - Model's goodness of fit: land share occupied by crop. . . . . . . . . . 21

Figure 3 - Changes in Crop Land Shares - A2 Climate vs. Baseline . . . . . . . . 32

Figure 4 - Changes in Crop Land Shares - B1 Climate vs. Baseline . . . . . . . . 33

Figure B.1-Brazil's Macro-regions . . . . . . . . . . . . . . . . . . . 52

Figure C.1 - Model's goodness of fit per crop: land share occupied by crop . . . . . 55

Figure C.2-Model's goodness of fit (Model with 10 crops): land share occupied by

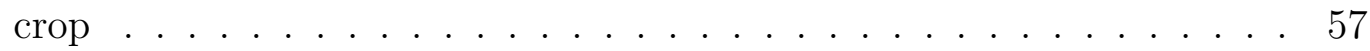

Figure C.3-Model's goodness of fit per crop (Model with 10 crops): land share occupied by crop . . . . . . . . . . . . . . . . . . . 58 58 


\section{List of Tables}

Table 1 - 2006 Percentage of Area Occupied by Crop . . . . . . . . . . . . . . . 13

Table 2 - 2006 Percentage of Crop Yield Value . . . . . . . . . . . . . . 14

Table 3 - Estimate of Land Share Elasticity Parameter . . . . . . . . . . . . . 20

Table 4 - Land Share Elasticity Estimation: First Stage on Prices . . . . . . . . . 20

Table 5 - PPML estimates of cost parameters . . . . . . . . . . . . 22

Table 6 - Estimating the Parameters in the Indirect utility: Second Stage . . . . 26

Table 7 - Estimating the Parameters in the Indirect utility: First Stage IV Coefficients on Wage Growth . . . . . . . . . . . . . . 26

Table 8 - Estimating the Labor Demand Parameters: Second Stage . . . . . . . . 27

Table 9 - Estimating the Labor Demand Parameters: Fist Stage IV Coefficients on Labor Force Growth . . . . . . . . . . . . . . . . . . . . 27

Table 10 - Estimating the Housing Market Parameters: Second Stage . . . . . . . 28

Table 11 - Estimating the Housing Market Parameters: First Stage IV Coefficients 29

Table 12 - Predicted Changes in Agriculture Land Shares by Crops . . . . . . . . . 34

Table 13 - Simulated impact of climate change on aggregate migration rates . . . . 35

Table 14 - Simulated impact of climate change on agricultural shares . . . . . . . . 36

Table 15 - Simulated impact of climate change on macro-regions' migration rates . 36

Table 16 - Simulated impact of climate change on macro-regions' agricultural shares 36

Table 17 - Simulated impact of climate change on aggregate workers' welfare . . . . 37

Table 18 - Simulated impact of climate change on macro-regions' worker welfare . 37

Table B.1-GAEZ Crop Productivities Distribution (t/ha) . . . . . . . . . . . . 53

Table C.1-International Trade Exposure Index . . . . . . . . . . . . . . . 54

Table C.2-Land Share Elasticity: First Stage . . . . . . . . . . . . . . . . 54

Table C.3-Land Share Elasticity . . . . . . . . . . . . . . . . . . . 55

Table C.4-Land Share Elasticity: First Stage on Prices . . . . . . . . . . . . . 56 


\section{Introduction}

Climate change is one of the major concerns of the current time as climate affects people's lives, and we expect a warmer climate in the future. Even though countries and international organizations discuss mitigation actions, there is no consensus on the mechanisms to curb international Greenhouse Gas (GHG) emissions. Therefore, the most likely scenario is that we would have to adapt to a warmer climate in the future. Many papers investigate how agents will adapt to a warmer climate, from the change in energy use (Mansur, Mendelsohn \& Morrison, 2008; DePaula \& Mendelsohn, 2010) ${ }^{1}$, the increase in migration (Oliveira \& Pereda, 2020; Sinha, Caulkins \& Cropper, 2018) ${ }^{2}$, to changes in crops (Costinot, Donaldson \& Smith, 2016; Seo \& Mendelsohn, 2008) ${ }^{3}$. However, this literature has mainly focused on one single channel of adaptation to climate change. An additional challenge that accounting for several adaptation mechanism in one analysis brings is the need to consider the cross-effects between the different adaptation channels. This, in turn, may have relevant implications on the predicted impacts of climate change.

This study provides a unique tractable model that integrates both migration and agricultural adaptation as mechanisms that respond to climate change. Our approach allows us to comprehend how these two mechanisms interact with each other and to assess their relative impacts. We use several Brazilian microdata to do that. The country offers an interesting setting due to its continental dimensions and its spatial diversity in terms of climatic and agricultural conditions, which implies that regions are likely to be affected differently. We employ our spatial equilibrium model features to assess the impacts of climate change on internal migration, the share of employment in agriculture, the spatial distribution of crops, and a welfare measure. We also simulate counterfactual exercises to measure the impacts of migration and crop change separately as mechanisms of economic adaptation. Furthermore, we evaluate results at a regional level, which reveals the potential of climate change as a driver of regional inequalities.

Our spatial equilibrium model builds on Oliveira \& Pereda (2020) which employs discrete-choice techniques to model workers' locational choice. A worker in our model chooses to live and work in the location and sector that maximizes her utility, considering a migration cost if she leaves her location of origin. The utility extracted from a locationsector pair is a function of local attributes - sector's wage, housing rental price, climatic and

1 As a response to changes in temperatures, households and firms may rely more or less on cooling or heating with implications on energy demand.

2 Changes in climatic amenities and economic conditions have the potential to spur migration.

3 In the agricultural sector, because sizable and spatially heterogeneous changes in climate are expected, crops that once were suitable to a certain region may then be suitable to another as agricultural productivity is reshaped. Hence, farmers may have an opportunity to adapt to climate by changing crops. 
non-climatic amenities - as well as a sector of employment amenity and an idiosyncratic taste shock. Furthermore, our model incorporates two important novel features: agriculture producers can reallocate their inputs across crops as a new form of adaptation to climate change, and the housing market is affected by a new land value channel. To maximize profits, farmers choose which crops to produce and how inputs are allocated, similarly to Costinot, Donaldson \& Smith (2016). As both developers and farmers use the land to produce, land value affects housing production costs, thus impacting housing prices. Hence, climate change has one direct - amenity value - and two indirect channels - agricultural wages and housing prices - which can affect locational choice, with the additional feature that agriculture adaptation affects the indirect channels.

The mechanisms by which our modeled economy responds to climate change can be laid out in a series of steps. First, climate change has a direct impact on climatic amenities and crop productivities. Farmers respond by reallocating their inputs according to the new optimal set of crops for the new climate. As a result, changes in agriculture demand for labor and land impact agricultural wages and housing rental prices. Workers then evaluate their prospective indirect utilities based on the new climatic amenities, wages, and housing prices and choose their location-sector pairs considering migration costs. As workers migrate, wages and rents adjust by local supply and demand, which, in turn, further alter locational choices. Therefore, our analysis accounts for general equilibrium effects of population re-sorting. A new equilibrium is reached when no one has incentives to migrate anymore.

Beyond the considerable impacts of climate change on the spatial distribution of people and economic activity, Brazil is also an ideal setting for our study due to the availability of data on internal migration flows in the Brazilian population censuses. Moreover, as a considerable share of the country's labor force is employed in agriculture $(23 \% \text { in } 2010)^{4}$, it is especially important to understand how climate change will affect this population and what role agricultural adaptation will have within this context. Furthermore, the Brazilian agricultural census also provides necessary data to estimate farmers' adaptation to climate change via crop choice.

We begin to identify the parameters of our model by the agriculture firm. We use Brazilian agricultural census cross-section data and data on attainable crop yields from GAEZ (Global Agro-Ecological Zones) to estimate the cropland share elasticity to price and productivity. Then we estimate the parameters in our locational choice model following a two-step estimation procedure (Oliveira \& Pereda, 2020; Berry, Levinsohn \& Pakes, 2004; Timmins, 2007). In the first step, we exploit the information on migration flows developed from our 1980-2010 population censuses panel data to estimate the location-sector specific components of workers' indirect utilities and our parameterized migration costs. Then we

4 According to data from the 2010 Brazilian Population Census. 
use the indirect utilities estimated in the first step, along with data on wage, rents, and climate, to estimate the marginal utilities of income and climatic amenities. Finally, we estimate the parameters in the equations that characterize the equilibrium in the labor and housing market. We use instrumental variables to overcome endogeneity when estimating the cropland share elasticity, the marginal utility of income, and the parameters in the labor and housing market equations.

Once we have estimates of all our main structural parameters, we conduct a series of counterfactual exercises. We use the information on future crop productivity from GAEZ and temperature forecasts by the National Institute for Space Research (INPE) to carry out our simulations. We compare two future climate scenarios - a high-emissions scenario, A2, and a low-emissions one, B1, - to a simulation where we keep the baseline climate average climatic attributes during 1961-1990. Comparing crop choices under both future scenarios to the baseline ones, in aggregate terms, we can highlight a predicted reduction of land use for the production of Coffee, Sugarcane, and Wheat. An example of predicted change in the spatial distribution of crops in our model is that the South macro-region will experience a reduction of land use for Maize production and an increase in land use for Coffee production. ${ }^{5}$ In terms of migration, micro-region migration rates are $16.5 \%$ higher under scenario A2 and 18.25\% under scenario B1 than the scenario that maintains the baseline climate, with crop change barely altering these results. On the other hand, the adoption of crop change has a relevant impact on the share of employment in agriculture. With crop change, fewer people leave the agriculture sector in the high-emissions scenario (A2) than in the low-emissions one (B1), while the opposite happens if farmers do not adapt. This result is due to a more significant impact of crop change on the sector of employment in scenario A2. Furthermore, crop change also raises worker's welfare under both scenarios. However, crop change effects are much smaller than the comparative effect of introducing migration relative to a counterfactual scenario where migration costs were prohibitive.

When we analyze our results at a macro-region level, we see that climate change impacts the Brazilian macro-regions differently. Under both scenarios, the Northeast - one of the poorest macro-regions in Brazil - faces by far the most significant out-migration increases, $98.83 \%$ under scenario B1 and $78.24 \%$ under scenario A2 with crop change. At the same time, the Southeast macro-region has a decrease in out-migration under both scenarios. In terms of share of employment in agriculture, the North and Northeast macroregions face the most considerable reductions, with the Northeast reaching a decrease of $42.33 \%$ under scenario B1 with crop change compared to the baseline climate scenario. On the other hand, the South increases its share of employment in agriculture under both future scenarios when crop change is introduced, with crop change having a sizable effect on

5 A map of Brazil's macro-regions is available in Appendix Figure B.1. 
this phenomenon. In terms of workers' welfare, the Northeast macro-region is more heavily impacted by climate change, followed by the North and Midwest that present negative impacts under both scenarios. Nevertheless, the South and Southeast macro-regions have increased in workers' welfare under scenario A2.

Our study contributes to the literature on crop change and migration as mechanisms to cope with climate change. On the one hand, we explicitly provide simulations on how farmers are likely to reallocate their inputs across crops, which connects us to studies as Seo \& Mendelsohn (2008), Wang et al. (2010), Moniruzzaman (2015). However, these studies parameterize the relation between local climate attributes and crop profitability, leading to crop choice. In contrast, we rely on agronomic models to determine land suitability, a more similar approach to recent studies in the trade literature as Costinot, Donaldson \& Smith (2016) and Sotelo (2020). Moreover, empirical evidence of climate-driven crop substitution (Cui, 2020) help support the exercise conducted in our study.

On the other hand, regarding migration as a response to climate change, this study is closely related to Oliveira \& Pereda (2020). ${ }^{6}$ Nevertheless, beyond new advances in the theoretical model, as the inclusion of other forms of adaptation, our current analysis is conducted at a finer geographic level. Other previous related works as Timmins (2007) and Sinha, Caulkins \& Cropper (2018) also linked locational choice, climate amenities, and impacts of climate change. Moreover, our study relates to studies as Feng, Oppenheimer \& Schlenker (2012) and Cai et al. (2016) that explore the role of agriculture as a mechanism by which climate change spurs migration. Our work not only explores this channel but also includes another source of adaptation within it.

This paper is organized as follows. In Chapter 2 we lay out the theoretical model that structures our quantitative analysis. Chapter 3 describes the datasets we use to measure our variables of interest, as well as the treatment and building of necessary data. In Chapter 4, we present our estimation strategies and the estimates of the structural parameters. Chapter 5 outlines the main mechanisms of our counterfactual simulations. Chapter 6 presents and discusses the results from our simulations. Chapter 7 concludes.

6 A series of studies examined migration as a strategy to cope with climate change: Findley (1994), Barrios, Bertinelli \& Strobl (2006), Saldaña-Zorrilla \& Sandberg (2009), Drabo \& Mbaye (2015), Marchiori \& Schumacher (2011) and Marchiori, Maystadt \& Schumacher (2012). However, most of these studies focus on partial equilibrium modeling. In contrast, the analysis in Oliveira \& Pereda (2020) and this study follow a general equilibrium approach. Furthermore, many of these studies focus on extreme events, as opposed to long-term climate change. 


\section{Model}

The basis for our analysis is a spatial equilibrium model in which workers can choose a location to live and a sector of work while farmers can choose crops to be produced at each parcel of land in a location. Workers choose location and sector considering wages, local prices (housing), amenities provided by location and sector, as well as costs of migrating from a location to another and idiosyncratic tastes shocks. Farmers choose how they allocate resources on crop production based on local farm-gate prices for each crop and attainable crop yields. Climate impacts crop choice by affecting differently crops productivities at each location. Also, because land value is a function of marginal land productivity in agriculture, and as housing also depends on land, climate indirectly impacts housing prices. The workers' decision is affected by climate via three channels: (i) amenity value of locations, (ii) wages offered in the agriculture sector and (iii) housing prices at the location.

\subsection{Locational Choice}

The fundamentals of our locational choice model draws from Oliveira \& Pereda (2020). Consider a country with $J$ locations. Each location $k$ offers two employment sector, agriculture and non agriculture, indexed by $s=\{r, u\}$. At time $t$, a worker $n$ living in location $k$ and working in sector $s$, receiving wage $w_{k s t}$, consumes a bundle of agriculture and non-agriculture goods traded nationally, $B_{k s t}$, and local specific goods (represented by housing), $H_{k s t}$, costing respectively $P_{t}$ and $r_{k t}$. The worker also enjoys local amenities, which are divided into climate, $C_{k t}$, non-climate, $E_{k t}$, and sector-of-employment amenities, $S_{s t}$. Preferences over consumption of goods and housing are Cobb-Douglas type. Workers choose quantities $\left\{B_{k s t}, H_{k s t}\right\}$ to maximize their utilities under the budget constraint $P_{t} B_{k s t}+r_{k t} H_{k s t} \leq w_{k s t}$, this yields the following indirect utility ${ }^{7}$ :

$$
V_{k s t}=V_{t} w_{k s t} r_{k t}^{-\lambda_{l}} e^{\lambda_{C} C_{k t}} e^{\lambda_{E} E_{k t}} e^{\lambda_{S} S_{s t}},
$$

where $V_{t}=\lambda_{l}^{\lambda_{l}}\left(1-\lambda_{l}\right)^{\left(1-\lambda_{l}\right)} P_{t}^{-\left(1-\lambda_{l}\right)}$.

$\overline{7}$ A worker chooses quantities $\left\{B_{k s t}, H_{k s t}\right\}$ that solve the following problem:

$$
\begin{gathered}
\max B_{k s t}^{1-\lambda_{l}} H_{k s t}^{\lambda_{l}} e^{\lambda_{C} C_{k t}} e^{\lambda_{E} E_{k t}} e^{\lambda_{S} S_{s t}} \\
\text { s.t } P_{t} B_{k s t}+r_{k t} H_{k s t} \leq w_{k s t},
\end{gathered}
$$

which results in the indirect utility

$$
V_{k s t}=\left(\frac{\lambda_{l} w_{k s t}}{r_{k t}}\right)^{\lambda_{l}}\left(\frac{\left(1-\lambda_{l}\right) w_{k s t}}{P_{t}}\right)^{\left(1-\lambda_{l}\right)} e^{\lambda_{C} C_{k t}} e^{\lambda_{E} E_{k t}} e^{\lambda_{S} S_{s t}} .
$$


A worker with origin in $j$ who moves to $k$ pays a migration cost $\mu_{j k}$, which depends on $D_{j k}$, a vector of pairwise distance bins, following the function:

$$
\exp \left\{\mu_{j k}\right\}=\exp \left\{\mu_{f} 1\{j \neq k\}+\mu_{d} D_{j k}\right\}
$$

Thus, assuming that, before choosing a location and a sector, an individual $n$ draws a vector $\vartheta_{n k s t}$ of $J X 2$ i.i.d idiosyncratic taste shocks with Fréchet distribution , $P\left(\vartheta_{n k s t}<x\right)=\exp \left\{-x^{-\sigma}\right\}$, the utility this individual will derive from migrating from $j$ to $k$ to work in sector $s$ in period $t$ is:

$$
V_{n j k s t}=\frac{V_{k s t} \vartheta_{n k s t}}{\exp \left\{\mu_{j k}\right\}}
$$

When the individual $n$ stays in the same location - migrates from $j$ to $j-$, the migration cost can be expressed as $\exp \left\{\mu_{j j}\right\}=1$.

Each individual chooses to live and work in the location-sector that provides the higher indirect utility, it is $(k, s)=\arg \max _{l, q} V_{l q t} \exp \left\{-\mu_{j l}\right\} \vartheta_{\text {nlqt }}$. Because of our distribution assumption on $\vartheta_{\text {nlqt }}$, we can derive the probabilities of each location-sector being chosen: ${ }^{8}$

$$
\begin{aligned}
\pi_{j k s t} & =\operatorname{Pr}\left(V_{n j k s t} \geq V_{n j l q t} \forall l \neq k, \forall q \neq s\right) \\
& =\frac{\left(V_{k s t} \exp \left\{-\mu_{j k}\right\}\right)^{\sigma}}{\sum_{q \in\{r, u\}} \sum_{l=1}^{J}\left(V_{l q t} \exp \left\{-\mu_{j l}\right\}\right)^{\sigma}} .
\end{aligned}
$$

Given an initial distribution of the population, $N_{j}^{0}$, and assuming each worker supplies inelastically one unit of labor to their location-sector of choice at the current wage, the supply of labor at location $k$, sector $s$, period $t$ is:

$$
N_{k s t}=\sum_{j=1}^{J} N_{j}^{0} \pi_{j k s t} .
$$

\subsection{Agriculture and non-agriculture firms}

We consider two economic sectors, agriculture and non-agriculture, indexed by $\mathrm{s}=$ $\{\mathrm{r}, \mathrm{u}\}$. At each location $k$, an agricultural firm can produce $M$ different goods (crops), with quantities represented as $Q_{k r t}^{m}$, and a non-agricultural firm produces a composite good, with quantities $Q_{k u t} \cdot{ }^{9}$ Firms from both sector operate with Cobb-Douglas technologies.

8 Complete derivation of migration probabilities is available in Appendix A.1.

9 These are not necessarily final products, hence prices are not directly the prices paid by consumers for their nationally and local-specific traded goods. In fact, agriculture firms in our model produce exclusively primary goods sold at a farm-gate price with its own local-specific dynamics. We do not model explicitly how farm-gate prices affect final nationally-traded good prices as these do not play a main role in our final exercises. 


\subsubsection{Non-agriculture firm}

The non-agriculture firm uses only labor, $N_{k u t}$, as an input. The production is defined as:

$$
Q_{k u t}=A_{k u t} N_{k u t}^{\alpha_{u}}
$$

where $A_{k u t}=A_{k t} \exp \left\{\nu_{k u t}\right\}$ is the productivity composed by $A_{k t}$ location-wide determinants of productivity and $\nu_{k u t}$ location-sector specific shocks. We follow the simplifying assumption that climate has no direct impact on non-agriculture productivity. ${ }^{10}$ Firm's profit are characterized as:

$$
\Pi_{k u t}=p_{k u t} A_{k u t} N_{k u t}^{\alpha_{u}}-w_{k u t} N_{k u t} .
$$

Then, assuming competitive labor market, profit maximization determines equilibrium non-agriculture wages as:

$$
w_{k u t}=\alpha_{u} p_{k u t} A_{k u t} N_{k u t}^{-\left(1-\alpha_{u}\right)}
$$

\subsubsection{Agriculture Firm}

We assume that the technology to produce crop $m$ presents constant returns to scale. Production of agriculture firms takes place in perfectly divisible parcels of land $\omega$ referred as plots. The suitability of a plot $\omega$ in location $k$ for producing $m$ is captured by TFP $A_{k r t}^{m}(\omega) \geq 0$. Production of crop $m$ at plot $\omega$ is

$$
Q_{k r}^{m}(\omega)=A_{k r}^{m}(\omega)\left[N_{k r}^{m}(\omega)\right]^{\alpha_{r}}\left[L_{k r}^{m}(\omega)\right]^{1-\alpha_{r}},
$$

where $Q_{k r}^{m}(\omega)$ is the output of crop $m, N_{k r}^{m}(\omega)$ and $L_{k r}^{m}(\omega)$ are labor and land inputs. We assume cost shares of labor, $\alpha_{r}$, and land, $1-\alpha_{r}$, do not vary across crops. ${ }^{11}$

In the spirit of Eaton \& Kortum (2002), we assume that TFPs $A_{k r}^{m}(\omega)$ are independently drawn for each $(k, \omega)$ from a Fréchet distribution with parameter $\theta>1$ such that:

$$
\begin{aligned}
& \operatorname{Pr}\left(A_{k r t}^{1}(\omega) \leq a^{1}, \ldots, A_{k r t}^{M}(\omega) \leq a^{M}\right)= \\
& \exp \left\{-\gamma\left[\sum_{m \in M}\left(a^{m} / A_{k r t}^{m}\right)^{-\theta}\right]\right\},
\end{aligned}
$$

10 The absence of this channel could mean that our simulations understate the effects of climate change on migration and welfare. Evidence of weather/climate effects on non-agriculture wages for Brazil from Oliveira, Palialol \& Pereda (2021) points out that a $2 \%$ uniform increase in temperatures effect on non-agriculture wages would mean a $0.30 \%$ loss of GDP.

11 Our assumptions on agriculture firms' technology are close to a simplified version of Sotelo (2020) without intermediary inputs and where costs shares do not vary across crops. 
where $\gamma \equiv\left(\Gamma\left(1-\frac{1}{\theta}\right)\right)^{-\theta}$ and $A_{k r t}^{m} \equiv E\left[A_{k r t}^{m}(\omega)\right] \cdot{ }^{12}$ In a location where it is impossible to grow crop $m$, we set $A_{k r t}^{m}=0$. As $A_{k r t}^{m}$ is an average land suitability for crop $m$ across plots, a high value of $A_{k r t}^{m}$ suggests a high land quality in every plot in location $k$ for growing crop $m$. Within region $k$, between-plot dispersion in land quality decreases with $\theta$, which can be interpreted as an inverse measure of land heterogeneity.

The representative agricultural firm in location $k$ hires labor and rents land. The farmer decides how to allocate plots of land across crops and chooses the amount of labor employed in each plot. Consider $\Omega_{k}$ as the set of plots that are allocated to agriculture in location $k$. The producer's problem is to choose $\left\{N_{k r}^{m}(\omega), L_{k r}^{m}(\omega), \omega \in \Omega_{k}, \forall k\right\}$ to maximize profits:

$$
\max \sum_{m=1}^{M} p_{k r t}^{m} Q_{k r t}^{m}-\int_{\Omega_{k}} \sum_{m=1}^{M}\left[w_{k r t} N_{k r t}^{m}(\omega)+R_{k t} L_{k r t}^{m}(\omega)\right] \partial \omega
$$

where, for all $k$, total output of crop $m$ is:

$$
Q_{k r t}^{m}=\int_{\Omega_{k}} A_{k r t}^{m}(\omega)\left[N_{k r t}^{m}(\omega)\right]^{\alpha_{r}}\left[L_{k r t}^{m}(\omega)\right]^{1-\alpha_{r}} \partial \omega .
$$

Farmers' profit maximization, under our current assumptions, will imply three important features of our model. First, the ratio between land and labor remains fixed across every agriculture productive plot and across crops produced within a location $k$ at time $t$, which implies that the share of total land used to produce a given crop $m$ is equal to the share of total labor used in the same production. ${ }^{13}$ Second, each parcel $\omega$ of cultivated land is allocated to the crop which maximizes its marginal profit, and, because parcels $\omega$ of land form a continuum at each location $k$, the share of cultivated land by crop is equal to the probability that the crop is the maximizing crop at each parcel $\omega$ cultivated. Lastly, agriculture wage will act as a function of land-labor ratio and land use across crops inside a location $k$ at time $t$. A more detailed discussion and the whole profit maximization process is described in our Appendix A.

Land allocation across crops in location $k$ at time $t$, given profit maximization, are described in our model by $\eta_{k r t}^{m}=\operatorname{Pr}\left(m=\arg \max _{n} p_{k r t}^{n} A_{k r t}^{n}(\omega)\right)$. Given our distributional assumption on $A_{k r t}^{n}(\omega)$, this implies:

$$
\eta_{k r t}^{m}=\frac{\left(p_{k r t}^{m} A_{k r t}^{m}\right)^{\theta}}{\sum_{l=1}^{M}\left(p_{k r t}^{l} A_{k r t}^{l}\right)^{\theta}} .
$$

12 We demonstrate the land suitability expected value in the Appendix A.3.

13 Let $L_{k r t}^{m}$ be the amount of land used in location $k$ to produce crop $m$, and let $L_{k r t}=\sum_{n=1}^{M} L_{k r t}^{m}$ be the total amount of land used in agriculture in location $k$. Similarly, consider $N_{k r t}^{m}$ the quantity of labor in $k$ used to produce $m$ and $N_{k r t}$ the total labor used in $k$. Then, profit maximization implies

$$
\frac{L_{k r t}^{m}}{N_{k r t}^{m}}=\frac{L_{k r t}}{N_{k r t}} \forall m \rightarrow \frac{N_{k r t}^{m}}{N_{k r t}}=\frac{L_{k r t}^{m}}{L_{k r t}} \forall m
$$


Hence, the share of land in $k$ allocated to $m$ increases with the crop price, $p_{k r t}^{m}$, and with the average land suitability of crop $m$ to location $k, A_{k r t}^{m}$. When $\theta$ is large, land is more homogeneous and a given increase in a crop's price or average land suitability produces a larger shift in its land use.

The equilibrium wage in agriculture in location $k$ is described by the following Equation:

$$
w_{k r t}=\alpha_{r}\left(\frac{L_{k r t}}{N_{k r t}}\right)^{1-\alpha_{r}} \sum_{m=1}^{M} p_{k r t}^{m}\left(\eta_{k r t}^{m}\right)^{1-\frac{1}{\theta}} A_{k r t}^{m} .
$$

Thus, if an exogenous event increased the land-labor ratio, $\frac{L_{k r t}}{N_{k r t}}$, in a location $k$, making labor relatively more productive, we would witness an increase in agriculture wages. Because in our constant returns to scale setting a firm in equilibrium has zero profit and divides its revenue between inputs according to the parameter $\alpha_{r}$, then the optimal allocation of land across crops $\left\{\eta_{k r t}^{m}, m=1, \ldots, M\right\}$ also maximizes agriculture wage.

\subsection{Land and Housing Market}

Following Diamond (2016) and Oliveira \& Pereda (2020) we assume that each location has a well-developed housing market. Developers produce homogeneous housing units, $H_{k t}$, using land as input. Absentee landlords are the owners of land, which they rent to either developers or farmers. Let $L_{k t}^{h}$ be the quantity of land used by developers, and let $L_{k t}^{f}$ be the quantity of land used by farmers, the demand of land at location $k$ is $L_{k t}^{D}=L_{k t}^{h}+L_{k t}^{f}<\bar{L}_{k}$, where $\bar{L}_{k}$ is the full capacity of land supply in a location which we assume is not exhausted. In the asset market equilibrium, prices are set equal to the discounted value of rents, such that land rents are $R_{k t}=i_{t} P_{k t}^{\text {land }}$, and housing rents are $r_{k t}=i_{t} P_{k t}^{\text {house }}$.

From the workers' utility maximization problem we know that the demand for housing follows:

$$
r_{k t} H_{k t}^{D}=\lambda_{l}\left(w_{k r t} N_{k r t}+w_{k u t} N_{k u t}\right),
$$

and from the agricultural producers problem we have that:

$$
R_{k t} L_{k t}^{f}=\left(1-\alpha_{r}\right) N_{k r t}^{\alpha_{r}}\left(L_{k t}^{f}\right)^{1-\alpha_{r}} \sum_{m=1}^{M} p_{k r t}^{m}\left(\eta_{k r t}^{m}\right)^{1-\frac{1}{\theta}} A_{k r t}^{m} .
$$

We model the developers' technology as $H_{k t}=T_{k t}\left(L_{k t}^{h}\right)^{\phi} g\left(\lambda_{l} \sum_{s \in\{r, u\}} w_{k s t} N_{k s t}\right)$, where $g\left(\lambda_{l} \sum_{s \in\{r, u\}} w_{k s t} N_{k s t}\right)$ is intended to capture a "congestion cost" for housing supply. Hence, supposing $\phi<1$, profit-maximizing developers, renting land at a cost $R_{k t}$, will pick a land quantity

$$
L_{k t}^{h}=\left(\frac{\phi T_{k t} r_{k t} g\left(\lambda_{l} \sum_{s \in\{r, u\}} w_{k s t} N_{k s t}\right)}{R_{k t}}\right)^{\frac{1}{1-\phi}}
$$


Thus the supply curve of housing in location $k$ and time $t$ is

$$
H_{k t}^{S}=T_{k t}\left(\frac{\phi T_{k t} r_{k t} g\left(\lambda_{l} \sum_{s \in\{r, u\}} w_{k s t} N_{k s t}\right)}{R_{k t}}\right)^{\frac{\phi}{1-\phi}} g\left(\lambda_{l} \sum_{s \in\{r, u\}} w_{k s t} N_{k s t}\right) .
$$

Assuming that in each period housing demand and supply meet, $H_{k t}^{D}=H_{k t}^{S}$, the equilibrium housing rental price is defined by the expression:

$$
r_{k t}=\phi^{-\phi} T_{k t}^{-1} R_{k t}^{\phi}\left[\frac{\left(\lambda_{l} \sum_{s \in\{r, u\}} w_{k s t} N_{k s t}\right)^{1-\phi}}{g\left(\lambda_{l} \sum_{s \in\{r, u\}} w_{k s t} N_{k s t}\right)}\right] .
$$

We will use a reduced form of this expression in the rest of our paper:

$$
r_{k t}=\phi^{-\phi} T_{k t}^{-1} R_{k t}^{\phi}\left(\lambda_{l} \sum_{s \in\{r, u\}} w_{k s t} N_{k s t}\right)^{\psi} .
$$

A greater value of $\phi$ increases the effect of land rental costs on housing rents, and a greater value of $\psi$ increases the impact of housing demand on housing rental prices. 


\section{Data}

We combine several datasets in our analysis in order to gather information in four dimensions of our paper: (i) data on actual agriculture production, input uses, revenue and trade; (ii) data on model-predicted attainable yields under baseline and future climate scenarios; (iii) data on population distribution, wages and housing rents; and (iv) data on historical climate and climate forecast for future scenarios. This allows us to connect our model to actual data on the Brazilian economy and climate, capture and estimate our parameters of interest, as well as simulate counterfactual future scenarios.

Furthermore, a contribution of this study is our analysis of the effects of climate change on the Brazilian economy at a micro-region level. The finest level of geography in Brazil is the municipality. Municipalities are grouped into micro-regions, a finer geographic level than the meso-regions used in Oliveira \& Pereda (2020). While the meso-region is described by the Brazilian Institute of Geography and Statistics (IBGE) as an area of shared cultural history, natural resources, and connectivity, the micro-regions within it are defined by its specificities regarding the structure of agricultural, industrial, mining and fishing production. ${ }^{14}$ Hence, our use of micro-regions fits more adequately our more detailed analysis of the agriculture sector production.

\subsection{Agriculture Data}

The main use of agriculture data on our model is to identify the parameter $\theta$ in Equation 6, by this we are linking actual agricultural land use by crop to farm-gate prices and land suitability. Both farm-gate prices and agricultural land use are constructed using data from Brazilian 2006 agricultural census. Land suitability is measured using data from GAEZ (Global Agro-Ecological Zones). Additional agriculture data are used in our analysis: Brazilian Municipal Agriculture Surveys (PAM) from 1974, 1980, 1991, 2000 and 2010, as well as the Agrostat dataset from 2005, a dataset on Brazilian agribusiness international commerce statistics made available by Brazil's Ministry of Agriculture, Livestock and Food Supply.

\subsubsection{Agricultural Census}

The Brazilian agricultural censuses collect information on farming, livestock and agribusiness at the unit of production level, independently if production is destined to

14 See https://www.ibge.gov.br/en/ for details. 
sales or subsistence, and occurs in a periodicity close to decennial. ${ }^{15}$ However, although the data collection is made at a unit of production level, only aggregated data is available. We use municipal-level data on crop revenue, production and land use to construct our compatible micro-region data. ${ }^{16}$ Farm-gate prices are constructed by dividing crop revenue by crop production at the municipality level, then we aggregate to the micro-region level by finding the median price of each crop within the micro-region. ${ }^{17}$ The land share occupied by each crop in a micro-region is constructed by dividing the total area used to grow a crop by the sum of total areas used to grow the set of crops we are analysing. We use these information on median prices and land shares together with information on land suitability from the GAEZ dataset to identify the parameter $\theta$ in Equation 6. All nominal monetary values were converted to 2010 BRL (Brazilian Reais), and then converted to 2010 USD using the average exchange rate in 2010.

The 2006 Agricultural Census provides information on value, quantities and area occupied by 34 crops. The distribution of occupied area and value produced by crop can be observed on Tables 1 and 2. However, as our analysis depends on the use GAEZ data for attainable crop yields, we will narrow our crop sample to the ones observed in both datasets, leaving us with 18 crops: Banana, Cassava, Coconut, Coffee, Cotton, Cowpea, (Dryland) Rice, Groundnut, Maize, Onion, (Phaseoulus) Bean, Soybean, Sugarcane, Sunflower, Tobacco, Tomato, Wheat, and White Potato. This set of crops account for $95.90 \%$ of the area occupied by crops and $89.51 \%$ of total value of crops produced. Hence, our analysis captures the crops in which agricultural activity is mostly concentrated.

\subsubsection{Global Agro-Ecological Zones}

Our measure of land suitability of a crop to a location is used to identify the parameter $\theta$ in Equation 6. This measure comes from the GAEZ (Global Agro-Ecological Zones) dataset. The GAEZ project was developed by the International Institute for Applied System Analysis (IIASA) and the UN's Food and Agriculture Organization (FAO). The dataset uses state-of-the-art agronomic models and high resolution data on geographic characteristics such as soil, topography, elevation and climatic conditions to predict the

\footnotetext{
15 Although the Brazilian agricultural censuses follow a certain periodicity, they are not comparable among each other as different censuses have different crop-year measures. The 2006 Agricultural Census was conducted in 2007 collecting information about the agricultural production from the previous calendar year, while the 1995-1996 Agricultural Census utilized a crop-year from August 1995 to July 1996 and the 2017 Agricultural Census was based on a crop year from October 2016 to September 2017.

16 During our period of analysis, Brazil had a large increase in the number of municipalities, with older municipalities being divided into new ones. The micro-region geographical division was only introduced in 1989, not obeying older municipal border that were not in place anymore. Hence, in our analysis we grouped municipalities back into their older 1970 borders and allocated them into our new "compatible micro-regions" that aim to follow Brazil's official micro-region division.

17 Using median prices can reduce the impact of measurement error of farm-gate price in a given municipality within the micro-region when compared to using a mean price measure.
} 
Table 1 - 2006 Percentage of Area Occupied by Crop

\begin{tabular}{cccccc}
\hline \hline & Crop & Area $(\%)$ & & Crop & Area $(\%)$ \\
\hline 1 & Soybean & 35.149 & 18 & Castor Bean & 0.214 \\
2 & Maize & 23.013 & 19 & Grape & 0.139 \\
3 & Sugarcane & 10.879 & 20 & White Potato & 0.126 \\
4 & Rice & 4.772 & 21 & Groundnut & 0.118 \\
5 & Cowpea & 4.322 & 22 & Pineapple & 0.094 \\
6 & Coffee & 3.997 & 23 & Lemon & 0.069 \\
7 & Beans & 3.964 & 24 & Apple & 0.066 \\
8 & Cassava & 3.364 & 25 & Passion Fruit & 0.056 \\
9 & Wheat & 2.541 & 26 & Tangerine & 0.053 \\
10 & Cotton & 1.459 & 27 & Tomato & 0.051 \\
11 & Orange & 1.429 & 28 & Palm Heart & 0.043 \\
12 & Cocoa & 1.217 & 29 & Black Pepper & 0.040 \\
13 & Tobacco & 1.125 & 30 & Sunflower & 0.040 \\
14 & Banana & 0.720 & 31 & Papaya & 0.036 \\
15 & Watermelon & 0.314 & 32 & Melon & 0.031 \\
16 & Onion & 0.267 & 33 & Peach & 0.030 \\
17 & Coconut & 0.241 & 34 & Guava & 0.023 \\
\hline
\end{tabular}

Note: This table contains information on all 34 crops that present occupied area in the 2006 Agricultural Census. Values are percentage of occupied area by crop at a national level. Data source: 2006 Agricultural Census.

obtainable yield by a given crop at high-resolution grid cells - approximately $10 \mathrm{~km} \times 10$ $\mathrm{km}$ - covering the the surface of the earth. The GAEZ dataset is available both under a baseline climatic condition - using historical climate spanning from year 1961 to 1990 and under climate change scenarios used by the UN's Intergovernmental Panel on Climate Change (IPCC).

The GAEZ project offers attainable crop yields predictions under different assumptions of production technology and inputs. It is possible to obtain predictions based on assumption that farmers use irrigation or rain-fed water supply and that the input levels are low, intermediary or high. In a low input level farm, management is considered traditional, farming system is largely subsistence based, production uses labor intensive techniques and no use of nutrients, chemicals or disease control. In an intermediary input level farm, management is considered improved, farming system is partially market oriented, there is both subsistence and commercial production, and there is some use of fertilizers, chemicals and disease control. In a high input level farm, it is assumed an advanced management with a mainly market-oriented system, production uses high yielding crop varieties, mechanization and optimum use of nutrients, chemicals and disease control. A complete documentation on GAEZ methods is available in IIASA (2012). 
Table 2 - 2006 Percentage of Crop Yield Value

\begin{tabular}{|c|c|c|c|c|c|}
\hline & Crop & Value (\%) & & Crop & Value (\%) \\
\hline 1 & Sugarcane & 22.125 & 18 & Watermelon & 0.631 \\
\hline 2 & Soybean & 20.888 & 19 & White Potato & 0.359 \\
\hline 3 & Maize & 12.321 & 20 & Pineapple & 0.353 \\
\hline 4 & Coffee & 9.573 & 21 & Lemon & 0.349 \\
\hline 5 & Banana & 5.559 & 22 & Onion & 0.236 \\
\hline 6 & Rice & 4.452 & 23 & Passion Fruit & 0.211 \\
\hline 7 & Orange & 4.447 & 24 & Melon & 0.202 \\
\hline 8 & Cassava & 4.121 & 25 & Papaya & 0.195 \\
\hline 9 & Tobacco & 3.118 & 26 & Tangerine & 0.189 \\
\hline 10 & Cotton & 2.985 & 27 & Black Pepper & 0.181 \\
\hline 11 & Bean & 1.631 & 28 & Groundnut & 0.094 \\
\hline 12 & Grape & 1.092 & 29 & Peach & 0.086 \\
\hline 13 & Cowpea & 1.016 & 30 & Tomato & 0.085 \\
\hline 14 & Wheat & 0.942 & 31 & Guava & 0.072 \\
\hline 15 & Cocoa & 0.818 & 32 & Palm Heart & 0.045 \\
\hline 16 & Apple & 0.791 & 33 & Castor Bean & 0.032 \\
\hline 17 & Coconut & 0.786 & 34 & Sunflower & 0.016 \\
\hline
\end{tabular}

Note: This table contains information on all 34 crops that present occupied area in the 2006 Agricultural Census. Values are percentage of total crop yield value at a national level. Data source: 2006 Agricultural Census.

In our analysis, we restrict for grid cells in Brazil where the GAEZ indicated that there was already agriculture land use. We assumed water supply as rain-fed and intermediary input level. The 18 crops chosen in our analysis are the crops for which we have productivity data on GAEZ and cultivated area information on the 2006 agricultural census. Moreover, we gather data under the baseline climate (1961-1990), and under future climate scenarios for the period 2041-2070. The climatic predictions were generated by the Hadley Centre Coupled Model version 3 (HadCM3) for scenarios A2 (high emissions) and B1 (low emissions). We aggregate grid cell data into micro-region such that our land suitability measure is the average attainable crop yield (ton/ha) in the micro-region. ${ }^{18}$

\subsubsection{PAM and Agrostat}

We use data on agriculture crop revenue from the Brazilian Municipal Agriculture Surveys (PAM) from years 1980, 1991, 2000 and 2010, as well as data from crop land shares in 1974 to construct a shift-share instrument further discussed in Chapter 4 used to identify the parameters in Equation 11. Data are available at a municipal level for all

18 Under the baseline climate and our current assumptions, the distribution of attainable yields for all crops per micro-region can be seen in Table B.1. 
years, and are aggregated into our compatible micro-regions. All nominal monetary values were converted to 2010 BRL (Brazilian Reais), and then converted to 2010 USD using the average exchange rate in 2010 .

The Brazilian Municipal Agriculture Surveys are conducted yearly by the Brazilian Institute of Geography and Statistics (IBGE). The survey's objective is to inform at a municipality-crop level on quantities produced, planted and harvested area, and agricultural production value. The survey constitutes in an annual consolidation, at December $31^{\text {st }}$, of data collected during the whole year by a systematic survey of agricultural production (LSPA).

We also use additional data from Agrostat for data on exports and imports of crops and related products. Agrostat data is used to construct an instrument for farm-gate prices further discussed in Chapter 4. The Agrostat system is run by the Brazil's Ministry of Agriculture, Livestock and Food Supply. We used aggregated data at the national level for the year of 2005. Data is available at US dollars, however, conversion is not necessary for our use.

\subsection{Wages and Housing Rents}

We use microdata of the population censuses of 1980, 1991, 2000 and 2010 to calculate wages, housing rents, employment and migration flows. We aggregate our data into micro-regions. These information are used to estimate parameters in Equations 1, 2, 3 and 11.

As in Oliveira \& Pereda (2020), we restrict our sample to workers aged 25 to 60. This is done in order to exclude people who have not completed their schooling and people in retirement age. Wage is the monthly labor income in the main occupation divided by total monthly hours of work on the activity. The population censuses have information on both formal and informal sectors, and the available data on workers' sector of employment allow us to model the choice between agriculture and non-agriculture sector. Our housing rent measure is the amount paid by month in housing rents divided by the number of rooms. ${ }^{19}$ The censuses cover both formal and informal housing rents. We convert nominal wages and rents to 2010 BRL (Brazilian Reais) and then convert to 2010 USD using the average 2010 exchange rate.

Our work exploit a feature of the Brazilian population censuses, which is the availability of data on workers' municipality in a past period. For the years 1991, 2000 and 2010, we use municipality of residence five years prior to the census. For 1980, the information available is the municipality of the most recent move within the previous 10

19 The 2000 Census did not collect data on rents. To fill this gap, we use rental price data from the 1999 Brazilian Household Survey (PNAD). 
years.

\subsection{Weather and Climate Data}

Climate data is used to estimate the marginal utility of climate amenities, in Equation 1, and simulate its impact on workers' locational choice. We employ 10-yearaverages of climate variables that are taken over the census year and nine years previous to the census. This reflects the average exposure of workers to the climate in each micro-region.

The climatic variables measured are temperatures, rainfall and sunshine hours and are divided into Summer (Dec-Feb) and Winter(Jun-Aug) averages for each micro-region. These averages are calculated from historical daily weather station data from the Brazilian Institute of Meteorology. Daily weather station data were interpolated to calculate the micro-regions data.

To simulate the impact of climate change we employ 30-year-average climate. As in Oliveira \& Pereda (2020), our analysis cover only changes in temperature, because future sunshine hours predictions are not available and climate change data on rainfall are volatile and too sensitive to the choice of GCM (Global Climate Model) and scenarios. The baseline temperature is the 30-year-average summer and winter temperatures constructed from the daily weather stations data spanning the 1961-1990 period. Our data on future climate are sourced from the National Institute for Space Research (INPE). The INPE calculates regional climate change over South America by down-scaling the GMC of Hadley Centre. Scenarios from INPE are in line with scenarios from GAEZ. Again, we consider two scenarios: the pessimistic (high-emissions) scenario, A2, and the optimistic (low-emissions), B1. The A2 scenario describes a high population growth world (15 billion by 2100) with slower technological change and higher carbon emission, while the B1 scenario assumes a low increase in population that peaks in 2050 and the declines, with the introduction of cleaner technologies, this scenario's carbon emissions are equivalent to $65 \%$ of the total emissions in A2 scenario.

In Figure 1 we see, across micro-regions, the spatial distribution of temperature changes under A2 and B1 scenarios relative to the baseline climate. There is large temperature variation across the country: while some micro-regions face a relatively small reduction in temperature in some scenarios and seasons, temperature is expected to rise in most of the country, specially in the Midwest, where some micro-regions are expected to see up to $8^{\circ} \mathrm{C}$ in summer average temperature. 
Figure 1 - Change in temperature (in degrees Celsius) in summer and winter, B1 and A2 scenarios

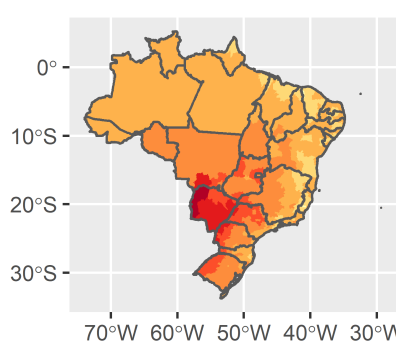

Summer, B1 Scenario

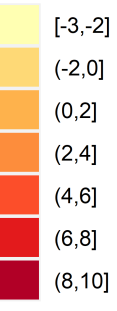

Winter, B1 Scenario
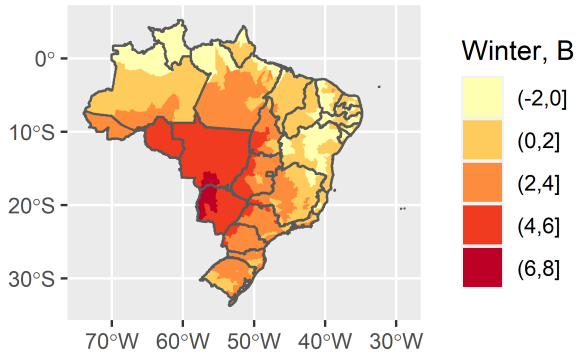

$(0,2]$

$(2,4]$

$(4,6]$

$(6,8]$

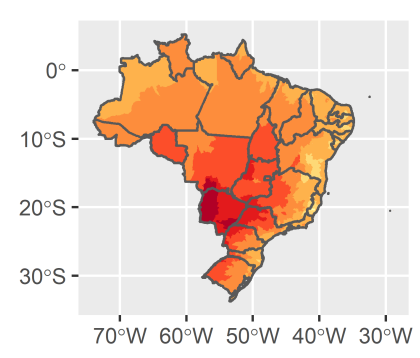

Summer, A2 Scenario

$[-3,-2]$
$(-2,0]$
$(0,2]$
$(2,4]$
$(4,6]$
$(6,8]$
$(8,10]$

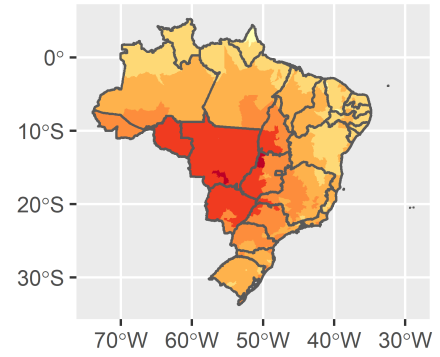

Winter, A2 Scenario

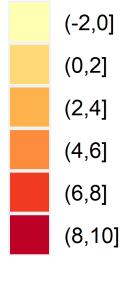

Notes: Change in temperature relative to the baseline. Baseline climate covers the 1961-1990 period; climate change forecast covers the 2041-2070 period. Data source: INMET and CPTEC/INPE 


\section{Estimation of Parameters}

From the development of our theoretical model, we have: a description of how workers choose their sector of work and living locations; the determination of non-agriculture and agriculture wages, and how farmers allocate land resources between crops according to agro-climatic conditions; and, a stylized land and housing market defining housing rental prices. Now, we present the empirical strategies used to estimate the main structural parameters.

The estimation of our model follows mainly two fronts: an estimation of the parameters from the agricultural firm problem, using mostly cross-section data from the agricultural census and GAEZ; and an estimation of the parameters from the locational choice model and housing market, with panel data from the population censuses, historical climatic data and municipal agricultural production survey data.

To capture the parameters governing the agricultural producers' problem, we can input $\alpha_{r}$ with information from agricultural firms expenses and $\theta$ can be estimated through Equation 6. We input the parameter $\alpha_{r}$ using the the information on agricultural spending shares from Avila \& Evenson (2010). Because, estimating $\theta$ directly from Equation 6 would mean incurring in a simultaneity bias, we employ an instrumental variable approach to estimate our parameter of interest.

To estimate the parameters from the locational choice model, following Oliveira \& Pereda (2020), we use a two-step approach proposed by Berry, Levinsohn \& Pakes (2004). First, we parameterize $\mu_{j k}$ as a function of distance, and use the data on bilateral migration flows,$\pi_{j k s}$, to estimate $v_{k s t}=\log V_{k s t}$ in Equation 2. Then, on the second step, we decompose the indirect utility by the effects of its components: wages, rents and amenities. First differences are used here to exploit the variation on actual changes of these variables. On sequence, non-agriculture labor demand and housing market elasticities are also estimated using a first-differences strategy with instrumental variables.

\subsection{Agricultural firm parameters}

We have two parameters to be captured from the agricultural firm problem: $\alpha_{r}$, the agriculture production elasticity to labor, and $\theta$, the land share elasticity to price and crops suitability.

We can input the value of $\alpha_{r}$ using information from Avila \& Evenson (2010). Given our assumptions on the agricultural firm technology $\alpha_{r}$ is the labor share of total costs, and $1-\alpha_{r}$ is the land share, with labor and land characterizing the only inputs. In 
Avila \& Evenson (2010) we have input share costs for a variety of inputs during the period 1981-2001. The labor share cost for Brazil in this study is $43.78 \%$ and cropland share cost is $17.26 \%$. If we consider only expenses on these two inputs, then the labor share cost is $\alpha_{r}=0.71$.

By applying $\log$ on the Equation 6, we can estimate the parameter $\theta$.

$$
\log \eta_{k}^{m}=\theta \log \left(p_{k}^{m} A_{k r}^{m}\right)+a_{k}+\xi_{k}^{m}
$$

where $a_{k}=\log \left(\sum_{l=1}^{M}\left(p_{k}^{l} A_{k r}^{l}\right)^{\theta}\right)$. However, a direct estimation of this equation would incur in a simultaneity bias. If crop prices result - at least in part - from a local market equilibrium, then land use $\left(\eta_{k}^{m} L_{k}\right)$ affects quantity produced which affects price if there is any finite elasticity of demand.

The overcome the simultaneity bias, we construct an instrument for agriculture farm-gate prices. We employ an interaction between distance to the closest major port for agricultural products and an index of crop exposure to international trade: $I^{m} \times$ $\log$ (Dist. Port). We use the study from Neto (2006) to determine what were the major Brazilian ports for agriculture near our year of analysis. ${ }^{20}$

For the crop exposure to international trade index, we gathered data on exports and imports of crops and its related products from the Agrostat system run by Brazil's Ministry of Agriculture, Livestock and Food Supply. We aggregated the data from 2005 by crop at the national level to create a measure of "international trade share" by crop. ${ }^{21}$ After this we divide the international trade shares by crop revenue shares to create an index of relative exposure to international trade, such that crops with a greater index value $I^{m}$ are more exposed to international markets: ${ }^{22}$

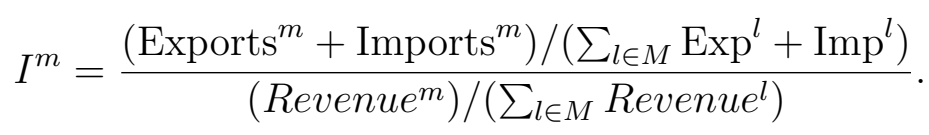

We estimate the parameter $\theta$ in Equation 12 using a 2SLS estimator with $I^{m} \times$ $\log$ (Dist. Port) as our instrumental variable for farm-gate prices. Results from second and first stage can be seen in Tables 3 and 4, and standard errors are clustered at the micro-region level. ${ }^{23}$ Our estimate for the parameter $\theta$ is 1.117 , which is lower than the value found for the same parameter for the Peruvian economy in Sotelo (2020), which

20 We consider the top five ports in terms of imports and exports of agriculture and wood products: Santos - SP, Paranaguá - PR, Rio Grande - RS, Itajaí - SC, and São Francisco do Sul - SC.

212005 is the year previous to our agricultural census data on prices and land shares.

22 A Table with the values for our international trade exposure index per crop is available in the Appendix C. Crops with an index above 1 represent a greater share of export and import related products than their national agricultural revenue share: Tobacco, Wheat, Soybean, Coffee and Sugarcane. Hence, those are crops relatively more exposed to international trade than crops like Cassava and Bean, for example, that have an index close to 0.

23 Results presented in Table 4 have farm-gate prices as dependent variable, our actual first stage estimates uses $\log p_{k}^{m} A_{k}^{m}$ as dependent variable. As expected, both estimates bring the same results, except by the fact that $\log A_{k}^{m}$ coefficient from Table 4 are added 1, as can be seen in Table C.2. 
suggests a greater within-region within-crop heterogeneity in land quality in the Brazilian micro-regions. This means that land-shares are relatively less responsive to shocks on prices or land suitability in our case.

Table 3 - Estimate of Land Share Elasticity Parameter

\begin{tabular}{|c|c|}
\hline & $\begin{array}{l}(1) \\
\mathrm{b} / \mathrm{se}\end{array}$ \\
\hline$\theta$ & $\begin{array}{c}1.117^{* * *} \\
(0.0880)\end{array}$ \\
\hline Obs. & 4585 \\
\hline Kleibergen-Paap Wald rk F stat. & 29.24 \\
\hline \multicolumn{2}{|c|}{$\begin{array}{l}\text { Notes: Prices are median farm-gate prices in- } \\
\text { side micro-region. Standard errors clustered } \\
\text { at the micro-region level. GAEZ data on } \\
\text { agricultural productivity restricted to areas } \\
\text { where agricultural land was reported. Data } \\
\text { source: Agricultural Census } 2006 \text {, GAEZ. } \\
\text { P-values: }{ }^{*} \mathrm{p}<0.1 \text {; }^{* *} \mathrm{p}<0.05 ;{ }^{* * *} \mathrm{p}<0.01 .\end{array}$} \\
\hline
\end{tabular}

Table 4 - Land Share Elasticity Estimation: First Stage on Prices

\begin{tabular}{lc}
\hline Dependent variable & $P_{k}^{m}$ \\
& $(1)$ \\
& $\mathrm{b} / \mathrm{se}$ \\
\hline$I^{m} \log$ Distance to Port & $-0.0554^{* * *}$ \\
& $(0.0103)$ \\
$\log A_{k r t}^{m}$ & $-0.433^{* * *}$ \\
& $(0.0271)$ \\
\hline Obs. & 4585 \\
Kleibergen-Paap Wald rk F stat. & 29.24 \\
\hline
\end{tabular}

Note: Prices are median farm-gate prices inside micro-region. Standard errors clustered at the micro-region level. GAEZ data on agricultural productivity restricted to areas where agricultural land was reported. Data source: Agricultural Census 2006, GAEZ, PAM 2005, Agrostat 2005. P-values: * p < $0.1 ;^{* *} \mathrm{p}<0.05 ;{ }^{* * *} \mathrm{p}<0.01$.

We present the results for goodness of fit of our land share predictions in Figure 2. Our model's current predictions do not match the data well, however there is still 
Figure 2 - Model's goodness of fit: land share occupied by crop.

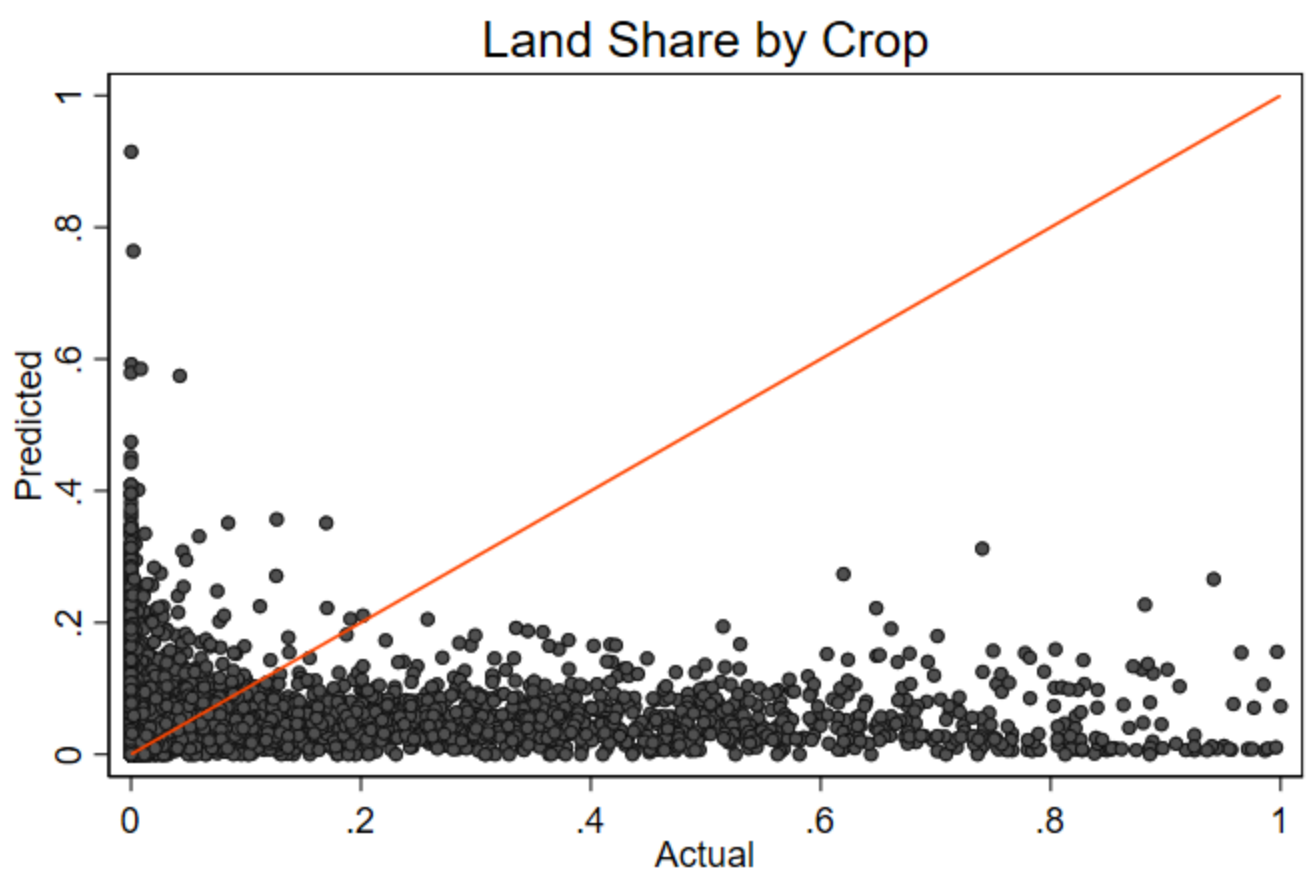

R-squared: 0.0000

Note: Each point is a share of agriculture land employed in the production of a crop in a micro-region. Data source: Agricultural Census 2006, GAEZ, Model estimates.

room for improvements in further versions of our work. Relaxing some of our current assumptions on agriculture may provide better results in the future. It may be the case that the assumptions that all crops are grown using the same input levels and factor cost shares are too restrictive. ${ }^{24,25}$ Nevertheless, despite not being a good predictor of land allocation across crop in the current format, our model can still be useful to measure changes in agricultural productivity and to have a sense of climate-change-driven changes in land allocation across crops as they are functions of land suitability. ${ }^{26}$

\subsection{Migration costs}

We parameterize migrations costs as:

$$
\mu_{j k}=\mu_{f} \mathbb{1}\{j \neq k\}+\mu_{d} D_{j k},
$$

${ }^{24}$ Bustos, Caprettini \& Ponticelli (2016) explores different crops technological advancements that can be labor or land saving. Authors use the GAEZ data and exploit the difference in gains across crops of changing input level.

25 Sotelo (2020) which develops a similar agriculture production model uses different factor cost shares per crop.

26 In the Appendix we present the Figures of goodness of fit separated by crops and the results when we estimate the model using only a subset of ten main crops. 
where $\mu_{f}$ is a fixed utility cost of migrating and $D_{j k}$ represents the Euclidean distance between locations $j$ and $k$ in $100 \mathrm{~km}$.

Taking log of Equation 2, we can treat the denominator as an origin-year fixed effect $\delta_{j t}$ and identify $\sigma v_{k s t}$ as a location-sector-year fixed effect, $\delta_{k s t}$. Thus, by adding an error term to capture unobservable components of migration cost, we reach the following Equation:

$$
\log \pi_{j k s t}=\delta_{k s t}+\delta_{j t}+\sigma \mu_{f} \mathbb{1}\{j \neq k\}+\sigma \mu_{d} D_{j k}+\sigma \epsilon_{j k s t},
$$

which is estimated using a Poisson ML strategy, following Oliveira \& Pereda (2020). Hence, our dependent variable is the number of people living in micro-region $k(k=1, \ldots, 529)$ and working in sector $s(s=r, u)$ in year $t(t=1980,1991,2000,2010)$ who originated from micro-region $j(j=1, \ldots, 529)$, which we use to estimate the $(529 \times 2 \times 4=4232)$ indirect utilities $\delta_{k s t}$ and the parameters of the migration cost function $\sigma \mu_{f}$ and $\sigma \mu_{d}$. The results in Table 5 suggest sizable fixed costs of migrating and substantial increases in costs with distance. In fact our estimation using data at micro-region level show even greater costs of relocating than the ones found in Oliveira \& Pereda (2020).

Table 5 - PPML estimates of cost parameters

\section{(1)}

\begin{tabular}{|c|c|}
\hline $\mathbb{1}\{j \neq k\}$ & $\begin{array}{l}5.73^{* * *} \\
(0.022)\end{array}$ \\
\hline Distance $_{j k}[2,4)$ & $\begin{array}{l}1.68^{* * *} \\
(0.029)\end{array}$ \\
\hline Distance $_{j k}[4,8)$ & $\begin{array}{c}2.91^{* * *} \\
(0.030)\end{array}$ \\
\hline Distance $_{j k}[8,16)$ & $\begin{array}{c}3.84^{* * * *} \\
(0.039)\end{array}$ \\
\hline Distance $_{j k}[16,32)$ & $\begin{array}{c}4.12^{* * *} \\
(0.038)\end{array}$ \\
\hline Distance $_{j k}[32, \max )$ & $\begin{array}{c}4.55^{* * *} \\
(0.13)\end{array}$ \\
\hline No. micro-region-sector pairs & $2,238,728$ \\
\hline \multicolumn{2}{|c|}{$\begin{array}{l}\text { Notes: Parameters generated using Poisson ML } \\
\text { estimator. Positive coefficient implies negative } \\
\text { impact on bilateral migration. } \mathbb{1}\{j \neq k\} \text { is an in- } \\
\text { dicator for whether the destination micro-region } \\
\text { is different from the origin location; Distance } j k \\
\text { is the Euclidean distance, in } 100 \mathrm{~km} \text {; the omit- } \\
\text { ted category is Distance } j k[0,2) \text {. Data source } \\
\text { Population Census, } 1980-2010 \text {. P-values: }{ }^{*} \mathrm{p}< \\
0.1 ;{ }^{* *} \mathrm{p}<0.05 ;{ }^{* * *} \mathrm{p}<0.01 \text {. }\end{array}$} \\
\hline
\end{tabular}




\subsection{Decomposing the indirect utility}

On our second step we capture our indirect utility parameters using our estimated $\hat{\delta}_{k s t}$ by applying a first differences strategy. This strategy cleans out possible time invariant unobservable location characteristics that are correlated with wages and amenities. With that we have:

$$
\Delta \hat{\delta}_{k s t}=\sigma\left(\Delta \log w_{k s t}-\lambda_{r} \Delta \log r_{k t}+\lambda_{C} \Delta C_{k t}+\lambda_{E} \Delta E_{k t}+\lambda_{S} \Delta S_{s t}\right)
$$

The parameter $\lambda_{r}$ is the share of housing on total income and is assigned as $\hat{\lambda_{r}}=0.2$ from Oliveira \& Pereda (2020), where it was calculated with data from the 2009 Household Budget Survey $(P O F)$. Non-climate and sector-of-employment amenities are not observed in the data, and thus, are controlled by macro-region-year fixed effects, meso-region trend controls and an agriculture dummy variable: $a_{\text {macro-region, } t}+a_{\text {meso-region }}+a_{s}$. Adding also an idiosyncratic amenity growth shock $\Delta \varphi_{k s t}$ to the equation, we estimate:

$\Delta \hat{\delta}_{k s t}=a_{\text {macro-region }, t}+a_{\text {meso-region }}+a_{s}+\sigma\left(\Delta \log w_{k s t}-0.2 \Delta \log r_{k t}+\lambda_{C} \Delta C_{k t}\right)+\Delta \varphi_{k s t}$.

\subsection{Non-agriculture labor demand}

Restricting our data to non-agriculture workers we can estimate the elasticity of non-agriculture wage through Equation 3. Applying log and taking first differences:

$$
\Delta \log w_{k u t}=\Delta \log p_{k u t}+\Delta \log A_{k u t}+\gamma \Delta \log N_{k u t}
$$

where $\gamma=-\left(1-\alpha_{u}\right)$. Again, as we do not observe directly non-agriculture prices and worker productivity, we assume: $\Delta \log p_{k u t}+\Delta \log A_{k u t}=b_{\text {macro-region }, t}+b_{\text {meso-region }}+\Delta \nu_{k u t}$, where $\Delta \nu_{k u t}$ is a location-period idiosyncratic shock. Hence, we estimate:

$$
\Delta \log w_{\text {kut }}=b_{\text {macro-region }, t}+b_{\text {meso-region }}+\gamma \Delta \log N_{k u t}+\Delta \nu_{k u t} .
$$

\subsection{Land-Housing market parameters}

Taking logs and using first difference on Equation 11, we have:

$$
\Delta \log r_{k t}=\phi \Delta \log R_{k t}+\psi \Delta \log \left(\lambda_{l} \sum_{s \in\{r, u\}} w_{k s t} N_{k s t}\right)-\Delta \log T_{k t} .
$$

We assume $-\Delta \log T_{k t}=c_{\text {macro-region, } t}+c_{\text {meso-region }}+\Delta \zeta_{k t}$, where $\Delta \zeta_{k t}$ is an locationperiod idiosyncratic shock. Because, we cannot observe directly land rents, we use the 
predicted first differences on log land rents. Hence, the equation estimated is:

$$
\begin{aligned}
\Delta \log r_{k t}= & \phi \Delta\left(\hat{\alpha}_{r} \Delta \log N_{k r t}-\hat{\alpha}_{r} \Delta \log L_{k t}^{f}+\Delta \sum_{m=1}^{M} p_{k r t}^{m}\left(\eta_{k r t}^{m}\right)^{1-\frac{1}{\theta}} A_{k r t}^{m}\right) \\
& +\psi \Delta \log \left(\hat{\lambda}_{l} \sum_{s \in\{r, u\}} w_{k s t} N_{k s t}\right)+c_{\text {macro-region }, t}+c_{\text {meso-region }}+\Delta \zeta_{k t}
\end{aligned}
$$

\subsection{Estimating indirect utility, labor and housing equation}

A direct estimation of Equations 14, 15 and 16 would fail to identify correctly our parameters due to endogeneity.

When estimating directly the effect of wage growth on location-sector indirect utility growth, we must remember that wage growth is impacted by labor supply growth, which is itself affected by indirect utilities via migration probabilities. Hence an increase in unobserved non-climate amenities, for example, is likely correlated with wage growth, biasing the estimator.

A direct estimation of the effect of non-agriculture labor supply growth on nonagriculture wages would also incur in bias. Consider any unobserved local wage shock, this would alter the indirect utility offered by the location-sector, which would affect migration probabilities that impacts the location-sector labor supply. This means any local shock on wages is likely correlated with labor supply growth.

At last, when estimating the impacts of land rent price growth and housing demand growth on housing rent growth, one must consider, for example, that housing rents can impact, via migration, the local agriculture labor supply, which is a determinant of both land rental prices and housing demand. Thus, an unobserved local housing rent shock is likely correlated with both our explanatory variables.

The first two instruments we present were already used in Oliveira \& Pereda (2020) under a similar setting. The first instrument is a labor demand shifter, known as Bartik shock (Bartik, 1991), which is calculated as:

$$
\Delta \operatorname{Bartik}_{k t}=\sum_{i n d}\left(\log w_{i n d,-k, t}-\log w_{i n d,-k, t-10}\right) \frac{N_{i n d, k, t_{0}}}{N_{k, t_{0}}}
$$

where $i n d$ indexes industry, $t_{0}$ represents a baseline year $(1970), w_{i n d,-k, t}$ is the average national wage in industry ind at time $t$ excluding location $k$ from the average, and $\frac{N_{i n d, k, t_{0}}}{N_{k, t_{0}}}$ is the share of the total employment in location $k$ and time $t_{0}$ that comes from industry ind.

The second instrument is a measure of "labor market access" (Morten \& Oliveira, 2016; Donaldson \& Hornbeck, 2016; Oliveira \& Pereda, 2020). Because migration is costly, labor supply on a location $k$ will be affected by the difficulty to be accessed from other 
localities. Also, consequently, the ease of access to a location will influence its wage, driven precisely by its exogenous effect on labor supply. We construct our measure of labor market access as:

$$
\Delta \log \mathrm{MA}_{k t}=\Delta \log \left(\sum_{j \neq k} \frac{1}{\hat{\mu_{j k}}} N_{j t}\right),
$$

where $\hat{\mu_{j k}}$ are our estimated migration costs, and $N_{j t}$ is the total number of people in year $t$ that originated from location $j$. The Bartik shocks and the labor market access instruments are employed to estimate the parameters $\sigma$ and $\gamma$ in Equations 14 and 15.

For our estimation of parameters $\phi$ and $\psi$ in Equation 16, besides our already used market access measure instrument, we employ as instruments: an indicative variable if the locality in 1970 was between the 5\% micro-regions with largest labor force; an agricultural revenue shift-share instrument; and the interaction between this agricultural revenue shift-share shock and the distance from the locality to the coast.

The agricultural revenue shift-share shocks are calculated as:

$$
\Delta \text { Agric.SSIV }=\sum_{m=1}^{M}\left(\log \left(1+\operatorname{Rev}_{-k, t}^{m}\right)-\log \left(1+\operatorname{Rev}_{-k, t-10}^{m}\right)\right) \eta_{k, 1974}^{m},
$$

where $R e v_{-k, t}^{m}$ is the total agricultural revenue from crop $m$ excluding revenue from locality $k{ }^{27} \eta_{k, 1974}^{m}$ is the share of crop-land occupied by crop $m$ in locality $k$ in 1974 , which pre-dates our main sample and is the farthest date achievable in our data. This instrument should capture exogenous growth in crop prices or in agricultural productivity for some crops (e.g. country-wide-available technological improvements on crop productivity). We also interact this agricultural shock with distance to coast, because of possible spatially heterogeneous effects. Notably in Brazil technological advancements impacted greatly the agricultural productivity in the Brazilian Midwest (Nehring (2016)), a macro-region distant to coasts.

Results from second and first stage estimates for parameters in Equation 14 are shown in Tables 6 and 7. Specification on column 1 uses only market access as instrument, on column 2 only the Bartik shocks are used, and in column 3 both instruments are included. Only the first specification passed the Weak Instrument test. An increase in summer temperatures reduce individual utility, while an increase in winter temperatures are perceived as a positive amenity. Increases in wages also impact positively individual indirect utilities.

Results from second and first stages estimates of parameter $\gamma$ from Equation 15 are seen in Tables 8 and 9. Again, first and second columns include only market access and Bartik shocks as instrument respectively, and the third column include both instruments. The third specification is our preferred one in this case. The estimated $\gamma$ corresponds to a $\hat{\alpha}_{u}=0.68$.

$\overline{27}$ We use $\log \left(1+R e v_{-k, t}^{m}\right)$ to handle with zeroes. 
Table 6 - Estimating the Parameters in the Indirect utility: Second Stage

\begin{tabular}{|c|c|c|c|}
\hline & $(1)$ & $(2)$ & (3) \\
\hline$\sigma$ & $\begin{array}{l}1.64^{* *} \\
(0.67)\end{array}$ & $\begin{array}{l}-3.93 \\
(9.29)\end{array}$ & $\begin{array}{l}1.52^{* *} \\
(0.65)\end{array}$ \\
\hline$\sigma \lambda_{\text {summer temp. }}$ & $\begin{array}{r}-0.22^{* * *} \\
(0.070)\end{array}$ & $\begin{array}{l}-0.30^{*} \\
(0.17)\end{array}$ & $\begin{array}{c}-0.22^{* * *} \\
(0.069)\end{array}$ \\
\hline$\sigma \lambda_{\text {winter temp. }}$ & $\begin{array}{c}0.21^{* * *} \\
(0.055)\end{array}$ & $\begin{array}{c}0.16 \\
(0.13)\end{array}$ & $\begin{array}{c}0.21^{* * * *} \\
(0.053)\end{array}$ \\
\hline Observations & 3,174 & 3,174 & 3,174 \\
\hline $\begin{array}{l}\text { Kleibergen-Paap rk Wald F-stat. } \\
\text { Hansen p-value }\end{array}$ & 17.6 & 0.25 & $\begin{array}{l}9.00 \\
0.25\end{array}$ \\
\hline
\end{tabular}

Notes: Standard errors clustered at the micro-region level. Each of the $529 \times 2 \times 4=4,232$ observations is a micro-region-sector-year. Parameters estimated on first-differenced data. Additional controls: summer and winter sunshine and rain; region-year FE; meso-region trend; and controls on sector, closeness to ocean, closeness to state capital and large labor force in 1970. Data source: CPTEC/INPE and Population Census, 1980-2010. P-values: ${ }^{*} \mathrm{p}<0.1 ;{ }^{* *} \mathrm{p}<0.05 ;^{* * *} \mathrm{p}<0.01$.

Table 7 - Estimating the Parameters in the Indirect utility: First Stage IV Coefficients on Wage Growth

\begin{tabular}{lccc}
\hline & $(1)$ & $(2)$ & $(3)$ \\
& & & \\
\hline$\Delta$ Bartik & & 0.13 & 0.13 \\
& & $(0.27)$ & $(0.27)$ \\
$\Delta \log$ MA & $-0.43^{* * *}$ & & $-0.43^{* * *}$ \\
& $(0.10)$ & & $(0.10)$ \\
\hline
\end{tabular}

Notes: Standard errors clustered at the microregion level. Each of the $529 \times 2 \times 4=4,232$ observations is a micro-region-sector-year. Parameters estimated on first-differenced data. Summer (Dec-Feb) and winter (Jun-Aug) temperatures are 10-year averages prior to the census year. Additional controls: summer and winter sunshine and rain; region-year FE; meso-region trend; and controls on sector, closeness to ocean, closeness to state capital and large labor force in 1970. Data source: CPTEC/INPE and Population Census, 19802010. P-values: ${ }^{*} \mathrm{p}<0.1 ;{ }^{* *} \mathrm{p}<0.05 ;{ }^{* * *} \mathrm{p}$ $<0.01$. 
Table 8 - Estimating the Labor Demand Parameters: Second Stage

\begin{tabular}{lccc}
\hline & $(1)$ & $(2)$ & $(3)$ \\
& $\mathrm{b} / \mathrm{se}$ & $\mathrm{b} / \mathrm{se}$ & $\mathrm{b} / \mathrm{se}$ \\
\hline$\gamma$ & -0.19 & -0.71 & $-0.32^{* *}$ \\
& $(0.12)$ & $(0.45)$ & $(0.13)$ \\
\hline Observations & 1587 & 1587 & 1587 \\
Kleibergen-Paap rk Wald F-stat. & 21.2 & 3.65 & 12.3 \\
Hansen p-value & & & 0.11 \\
\hline
\end{tabular}

Notes: Standard errors clustered at the micro-region level. Each of the $529 \times 2 \times 4=4,232$ observations is a micro-region-sector-year. Parameters estimated on first-differenced data. Additional controls: region-year FE; meso-region trend; and controls on sector, closeness to ocean, closeness to state capital and large labor force in 1970. Data source: Population Census, 1980-2010. P-values: ${ }^{*} \mathrm{p}<0.1{ }^{* *} \mathrm{p}<$ $0.05 ;{ }^{* * *} \mathrm{p}<0.01$.

Table 9 - Estimating the Labor Demand Parameters: Fist Stage IV Coefficients on Labor Force Growth

(1) (2) (3)

\begin{tabular}{cccc}
\hline$\Delta$ Bartik & & $-0.73^{*}$ & $-0.72^{*}$ \\
& & $(0.38)$ & $(0.38)$ \\
$\Delta \log$ MA & $0.63^{* * *}$ & & $0.63^{* * *}$ \\
& $(0.14)$ & & $(0.14)$ \\
\hline
\end{tabular}

Notes: Standard errors clustered at the micro-region level. Each of the $529 \times 2 \times$ $4=4,232$ observations is a micro-regionsector-year. Parameters estimated on firstdifferenced data. Additional controls: regionyear FE; meso-region trend; and controls on sector, closeness to ocean, closeness to state capital and large labor force in 1970. Data source: Population Census, 1980-2010. Pvalues: ${ }^{*} \mathrm{p}<0.1 ;{ }^{* *} \mathrm{p}<0.05 ;{ }^{* * *} \mathrm{p}<0.01$. 
Results from second and first stages estimates of parameters $\phi$ and $\psi$ from Equation 16 are seen in Tables 10 and 11. Instruments employed to identify the parameters in this Equation include: labor market access, an indicative variable for previously having a large labor force, the agriculture revenue shift share and its interaction with distance to coast. The third specification includes all instruments, while the first and second specification respectively leave out the agriculture revenue shift-share interaction with distance to coast and the agriculture revenue shift-share itself. From the third specification we estimate an housing rent elasticity to land rent of 0.12 , which indicates a relatively low importance of micro-regions' land prices to the formation of housing prices. Also, we estimate an housing rent elasticity to local aggregate housing demand of 0.74 , which suggests that rents do not respond much to increases in local housing demand.

Table 10 - Estimating the Housing Market Parameters: Second Stage

\begin{tabular}{lccc}
\hline & $(1)$ & $(2)$ & $(3)$ \\
& $\mathrm{b} / \mathrm{se}$ & $\mathrm{b} / \mathrm{se}$ & $\mathrm{b} / \mathrm{se}$ \\
\hline$\phi$ & 0.085 & $0.12^{*}$ & $0.12^{*}$ \\
$\psi$ & $(0.080)$ & $(0.071)$ & $(0.071)$ \\
& $0.78^{* * *}$ & $0.80^{* * *}$ & $0.74^{* * *}$ \\
Kleibergen-Paap rk Wald F-stat. & $(0.12)$ & $(0.12)$ & $(0.12)$ \\
Hansen p-value & 16.6 & 17.5 & 13.2 \\
\hline
\end{tabular}

Notes: Standard errors clustered at the micro-region level. Each of the $529 \times 2 \times 4=4,232$ observations is a micro-region-sector-year. Parameters estimated on first-differenced data. Hansen J statistic p-values of preferred specification is 0.24 . Differences on 10-year averages of accumulated rain, accumulated insolation and average temperature were used as controls. Additional controls: macro-region-year FE and meso-region trend. Data source: CPTEC/INPE, PAM (1974, 1980, 1991, 2000, 2010), Population Census, 1980-2010. P-values: ${ }^{*} \mathrm{p}<0.1$; $^{* *} \mathrm{p}<0.05$; $^{* * *} \mathrm{p}<0.01$. 
Table 11 - Estimating the Housing Market Parameters: First Stage IV Coefficients

\begin{tabular}{lcccccc}
\hline & \multicolumn{2}{c}{$(1)$} & \multicolumn{2}{c}{$(2)$} & \multicolumn{2}{c}{$(3)$} \\
& $\mathrm{R}$ & $H D$ & $\mathrm{R}$ & $H D$ & $\mathrm{R}$ & $H D$ \\
$\mathrm{~b} / \mathrm{se}$ & $\mathrm{b} / \mathrm{se}$ & $\mathrm{b} / \mathrm{se}$ & $\mathrm{b} / \mathrm{se}$ & $\mathrm{b} / \mathrm{se}$ & $\mathrm{b} / \mathrm{se}$ \\
\hline$\Delta \log M A$ & $1.44^{* * *}$ & $0.34^{* *}$ & $1.37^{* * *}$ & $0.33^{* *}$ & $1.39^{* * *}$ & $0.33^{* *}$ \\
& $(0.45)$ & $(0.15)$ & $(0.45)$ & $(0.15)$ & $(0.45)$ & $(0.15)$ \\
$1\left\{N^{1970}>=p(95)\right\}$ & 0.054 & $-0.16^{* * *}$ & 0.058 & $-0.16^{* * *}$ & 0.056 & $-0.16^{* * *}$ \\
& $(0.054)$ & $(0.022)$ & $(0.053)$ & $(0.022)$ & $(0.053)$ & $(0.022)$ \\
$\Delta$ Agric. SSIV & $0.81^{* * *}$ & $0.14^{* * *}$ & & & 0.24 & 0.056 \\
& $(0.14)$ & $(0.049)$ & & & $(0.45)$ & $(0.15)$ \\
$\Delta$ Agric. SSIV $\times \log$ Dist. Coast & & & $0.055^{* * *}$ & $0.0098^{* * *}$ & 0.040 & 0.0062 \\
& & & $(0.0096)$ & $(0.0033)$ & $(0.030)$ & $(0.0098)$ \\
\hline
\end{tabular}

Notes: Standard errors clustered at the micro-region level. Each of the $529 \times 2 \times 4=4,232$ observations is a micro-region-sector-year. Parameters estimated on first-differenced data. Differences on 10-year averages of accumulated rain, accumulated insolation and average temperature were used as controls. Additional controls: macro-region-year FE; meso-region trend. Data source: CPTEC/INPE, PAM (1974, 1980, 1991, 2000, 2010), Population Census, 1980-2010. P-values: ${ }^{*} \mathrm{p}<0.1 ;^{* *} \mathrm{p}<0.05 ;{ }^{* * *} \mathrm{p}<0.01$.

\section{Simulation}

Once we have in hand estimates of all our main structural parameters we may conduce our counterfactual simulations through a set of equilibrium equations. Nevertheless, a last additional difficulty is that we do not have data on non-climate and sector-ofemployment amenities. To overcome this issue, we follow Oliveira \& Pereda (2020) and estimate their sum, $X_{k s t}$, as the residual indirect utility after netting out the utility from components we have actual data: climate amenities, wages and housing rent prices. Following Oliveira \& Pereda (2020) we assume that the provision of these non-climate and sector-of-employment amenities will not vary over time. We employ the estimates of indirect utilities for the 2010 period, the wages and rents of the same period and the climate amenities of the baseline period $(1961$ - 1990) to construct our estimate of the residual indirect utility:

$$
\hat{X}_{k s t}^{b l i n e}=\hat{\delta}_{k s, 2010}-\hat{\sigma}\left(\log w_{k s, 2010}-\hat{\lambda}_{r} \log \mathrm{r}_{k, 2010}+\hat{\lambda}_{c} C_{k}^{b l i n e}\right) .
$$

Let $s c o=\{A 2, B 1\}$ indicate our climate change scenarios, where A2 is the pessimistic high-emission scenario, and B1 is the optimistic low-emission scenario. We need to calculate the initial values for agriculture wages and rent prices under the new climatic conditions:

$\log w_{k r, 0}^{s c o}=\log w_{k r, 2010}+\log \left(\sum_{m=1}^{M} p_{k}^{m} A_{k r}^{m, s c o}\left(\eta_{k}^{m, s c o}\right)^{1-\frac{1}{\theta}}\right)-\log \left(\sum_{m=1}^{M} p_{k}^{m} A_{k r}^{m, b l i n e}\left(\eta_{k}^{m, b l i n e}\right)^{1-\frac{1}{\theta}}\right) ;$ 
$\log r_{k, 0}^{s c o}=\log r_{k, 2010}+\phi \log \left(\sum_{m=1}^{M} p_{k}^{m} A_{k r}^{m, s c o}\left(\eta_{k}^{m, s c o}\right)^{1-\frac{1}{\theta}}\right)-\phi \log \left(\sum_{m=1}^{M} p_{k}^{m} A_{k r}^{m, b l i n e}\left(\eta_{k}^{m, \text { bline }}\right)^{1-\frac{1}{\theta}} \cdot\right)$

The initial value for non-agriculture wages is $w_{k u, 0}=w_{k u, 2010}$, because we assume climate has no direct effect on the non-agriculture sector. Hence, the initial value for the indirect utilities is:

$$
\hat{\delta}_{k s}^{s c o}=\hat{\sigma}\left(\log w_{k s, 0}^{s c o}-\hat{\lambda}_{r} \log r_{k, 0}^{s c o}+\hat{\lambda}_{c} C_{k}^{s c o}+\hat{X}_{k s t}^{b l i n e}\right) .
$$

For the migration probabilities we use our estimates on bilateral migration costs, $\hat{\sigma} \hat{\mu_{j k}}=\hat{\sigma}\left(\hat{\mu}_{f} \mathbb{1}\{j \neq k\}+\hat{\mu}_{d} D_{j k}\right)$, and the indirect utilities, such that:

$$
\hat{\pi}_{j k s}^{s c o}=\frac{\exp \left\{\hat{\delta}_{k s}^{s c o}-\hat{\sigma} \hat{\mu_{j k}}\right\}}{\sum_{q \in\{r, u\}} \sum_{l=1}^{J} \exp \left\{\hat{\left.\delta_{l q}^{s c o}-\hat{\sigma} \hat{\mu_{j l}}\right\}}\right.} .
$$

With these Equations, we can start to simulate the impact of climate change on the economy. The new climatic conditions exert initial effects on agricultural wages (through agriculture productivity), housing rents (through land prices that also respond to agriculture productivity), and climatic amenities, which impact workers indirect utilities derived from each locality-sector. In response, some workers may choose new localities and/or sector of employment. However as migration occurs, general-equilibrium effects make wages and rents adjust through the following Equations:

$$
\begin{gathered}
\log w_{k u, i+1}=w_{k u, 0}^{r e s}-\left(1-\alpha_{u}\right) \log N_{k u, i}, \\
\log w_{k r, i+1}=w_{k r, 0}^{r e s}-\left(1-\alpha_{r}\right) \log N_{k r, i}, \\
\log r_{k, i+1}=r_{k}^{r e s}+\psi \log \left(\lambda_{l} \sum_{s \in r, u} w_{k s, i} N_{k s, i}\right)+\phi \alpha_{r} \log N_{k, i},
\end{gathered}
$$

where $w_{k u, 0}^{r e s}=\log w_{k u, 0}+\left(1-\alpha_{u}\right) \log N_{k u, 0}, w_{k r, 0}^{r e s}=\log w_{k r, 0}^{s c o}+\left(1-\alpha_{r}\right) \log N_{k r, 0}$ and $r_{k}^{r e s}=\log r_{k, 0}-\psi \log \left(\sum_{s \in r, u} w_{k s, 0} N_{k s, 0}\right)-\phi \alpha_{r} \log N_{k, 0}$. New wages and prices induce more reallocation, which again incites changes in wages and rent prices. A new equilibrium is reached when population converges. 


\section{Results}

Once we have gathered the results from our counterfactual simulations, we can begin answering some questions. What changes in agricultural production and crop distribution do our model predict? What is the effect of climate change on migration and agriculture? To what extent does crop change as an adaptation to climate change influence those outputs? How different macro-regions are affected? And what are the implications in terms of welfare in our model? One by one, we will tackle all of these questions in this Chapter.

\subsection{Changes in Agriculture Production}

One of the novel contributions of our model is to consider the possibility of agricultural adaptation to climate change via crop choice, or, more precisely, via farmers' input allocation choices across crops. In Table 12, we observe the land shares occupied by the main crops under the baseline climate and how those land shares would change under the new climate scenarios. ${ }^{28}$ Changes follow the same sign under both future climate scenarios, with, generally, greater changes seen under scenario A2 (higher emissions). The crops that presented a higher predicted increase were: Cassava, Phaseoulus Bean, Dryland Rice, Maize and Cowpea. Only three of the main crops presented a decrease in land shares: Sugarcane, Coffee and Wheat.

We can also observe the spatial distribution of the change of land shares per crop in Figures 3 and 4. A subgroup of eight of our main crops were included in this analysis. Under both climatic scenarios it is possible to observe some reallocation of crops in the territory. For example, in both scenarios our model predicts that Maize will occupy less cultivated area in the South macro-region of Brazil, while Coffee is predicted to increase its occupation in the same macro-region; Soybean is predicted to slightly increase its occupied area in most of Brazil, with decreases concentrated mainly in the South, while Cassava is predicted to be more present in the South and less present in parts of the Northeast and North macro-regions.

Although our current analysis presents limitations that should be improved regarding the prediction of land shares, what drives changes in crops land shares in our model is solely changes in land suitability measured by GAEZ - because we maintain crop prices fixed -, hence, even being skeptical of the intensity of changes presented, it is possible to

28 The main crops are the 10 crops that occupied more agriculture area in the 2006 agricultural census, as we can see in Table 1, and were also in the GAEZ data. The term "Others" sums the area occupied by all remaining crops in our analysis, they are: Banana, Coconut, Groundnut, Onion, Sunflower, Tobacco, Tomato and White Potato. 
Figure 3 - Changes in Crop Land Shares - A2 Climate vs. Baseline
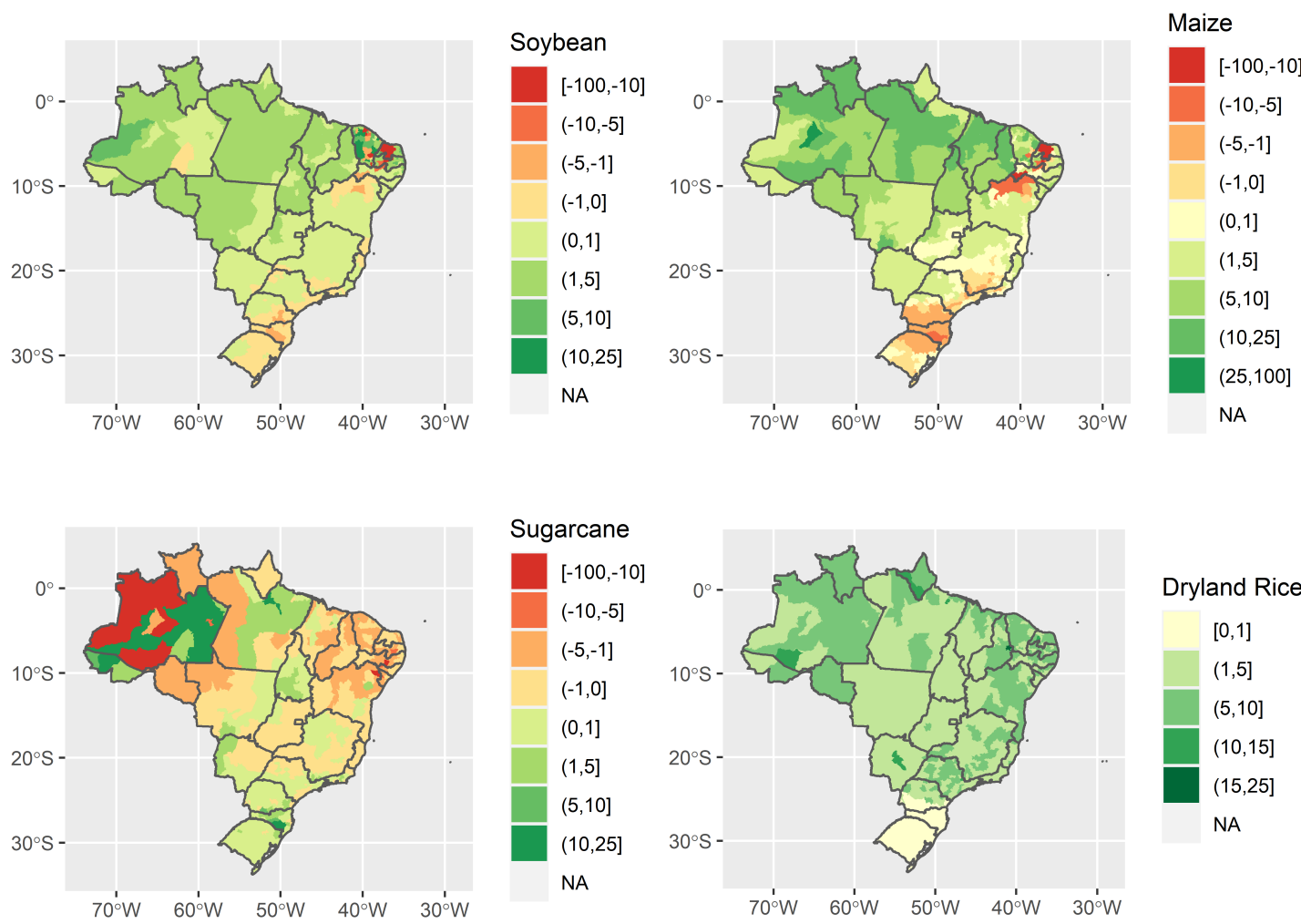

Dryland Rice
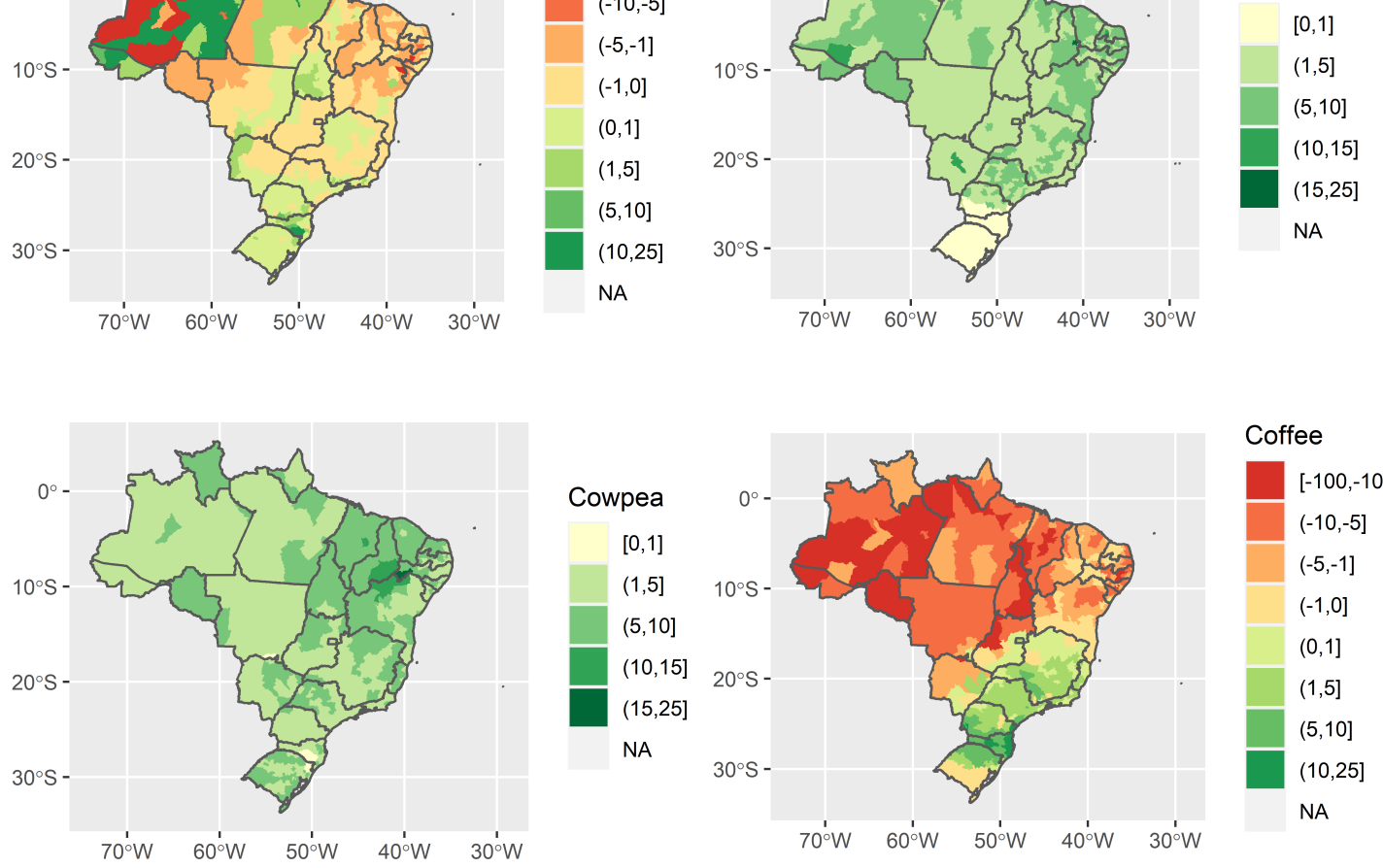

\section{Coffee}
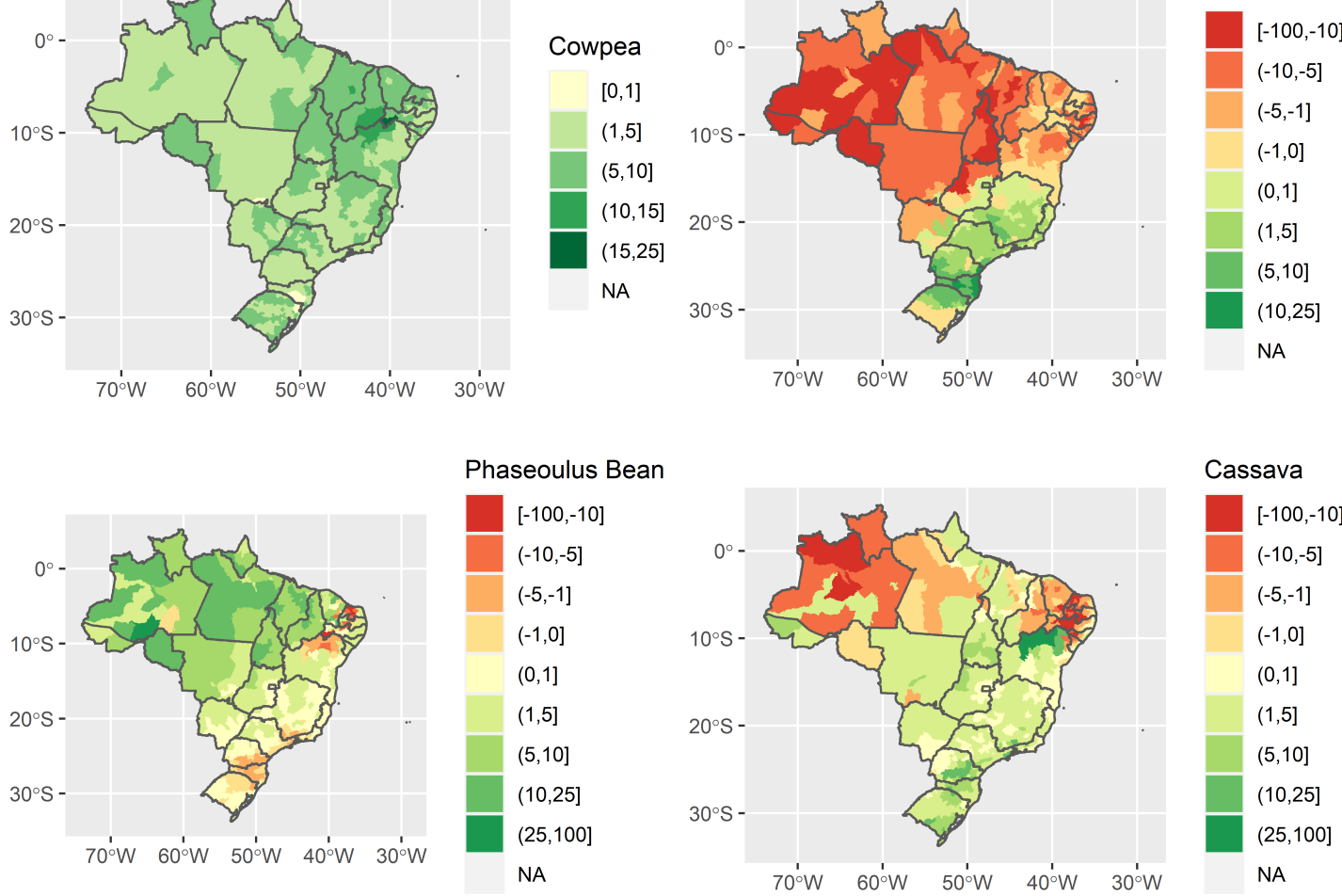

Notes: Changes in percentage points. Land Shares are our model's optimal land shares under each climate. Data source: Model estimates, GAEZ, 2006 Agricultural Census 
Figure 4 - Changes in Crop Land Shares - B1 Climate vs. Baseline
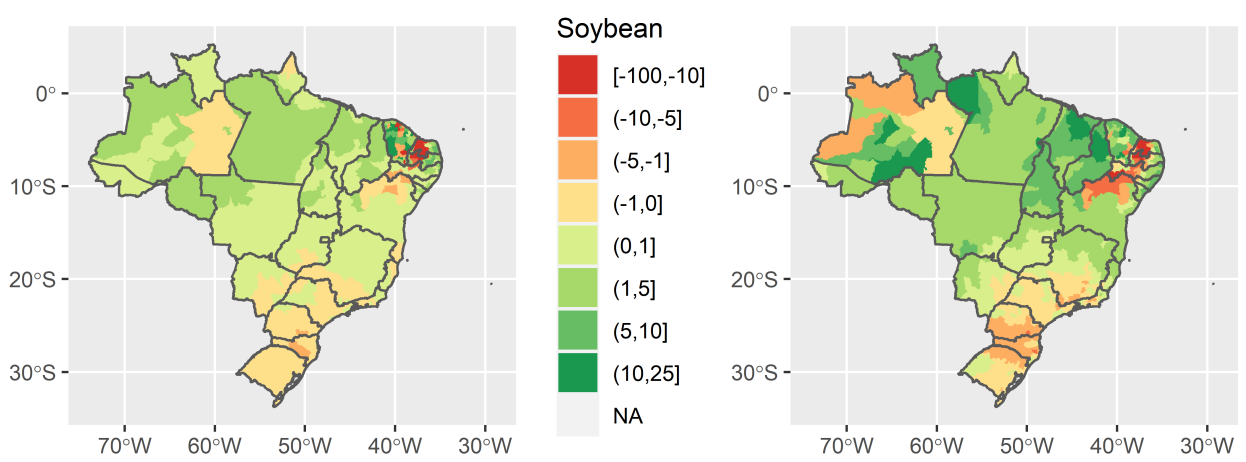

Maize
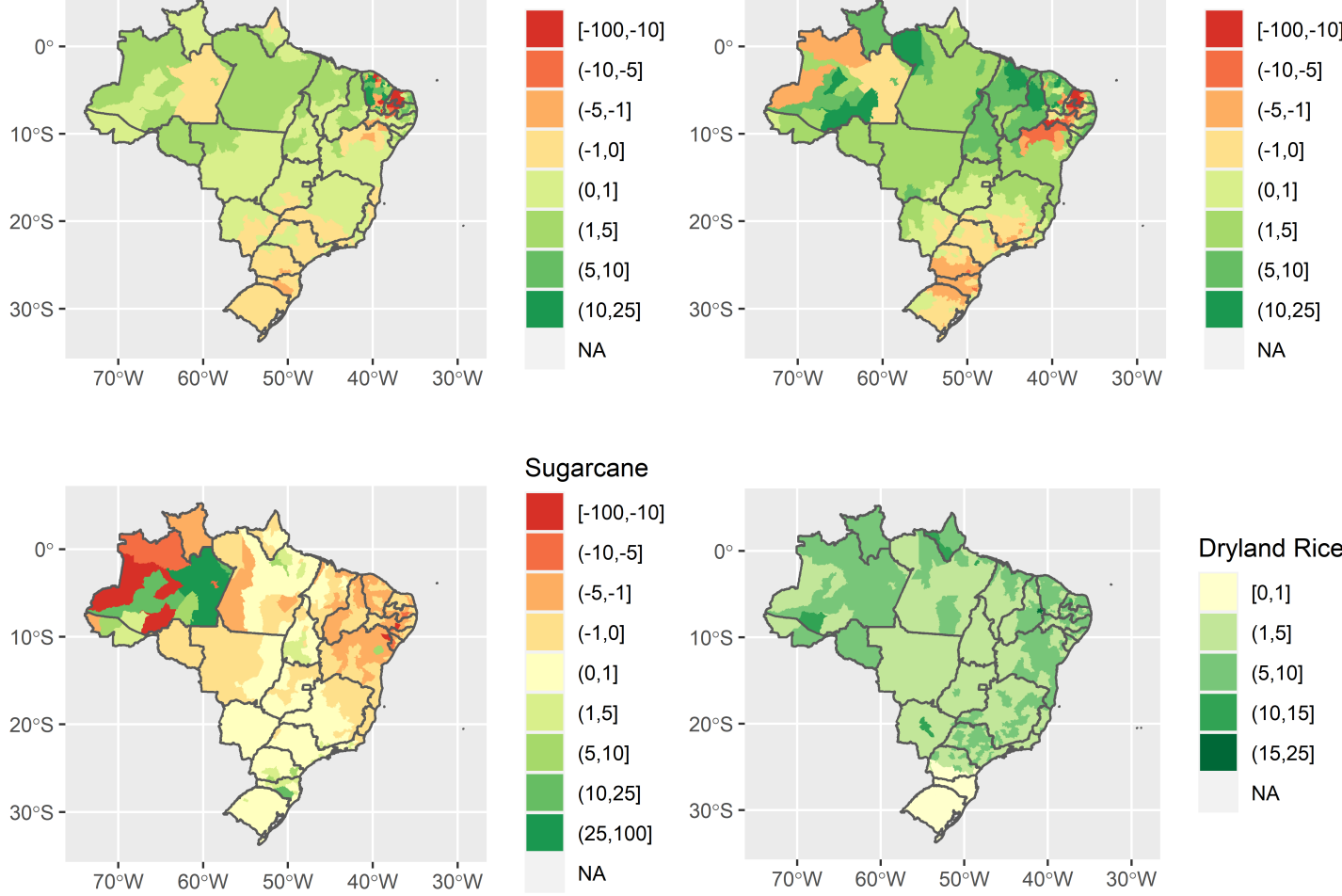

\section{Sugarcane}
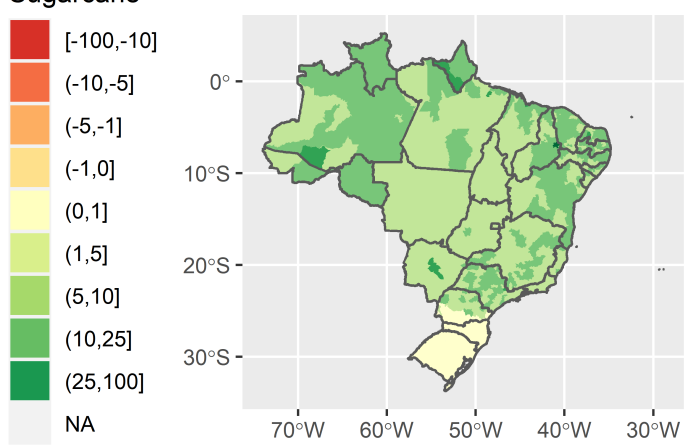

Dryland Rice
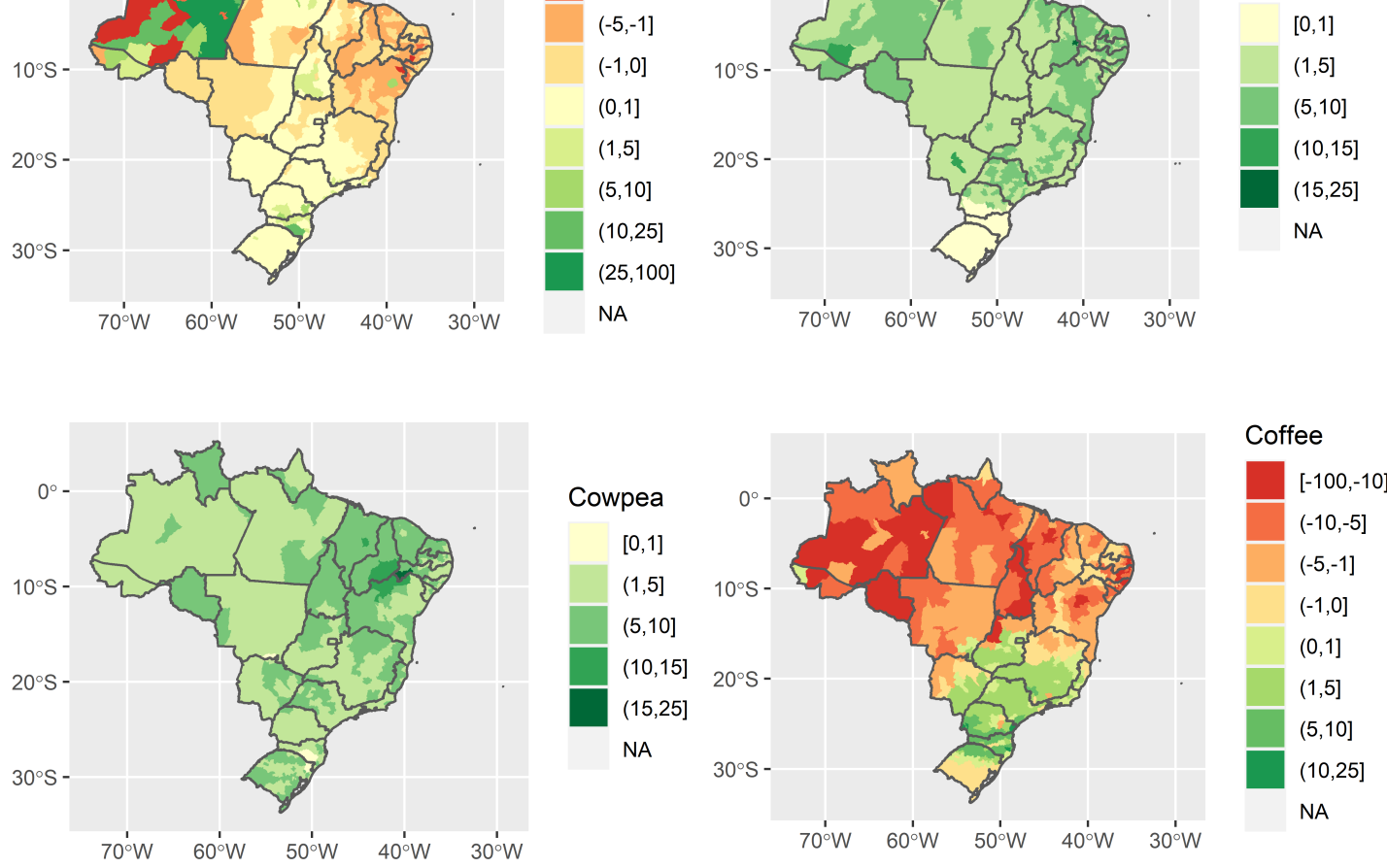

Coffee
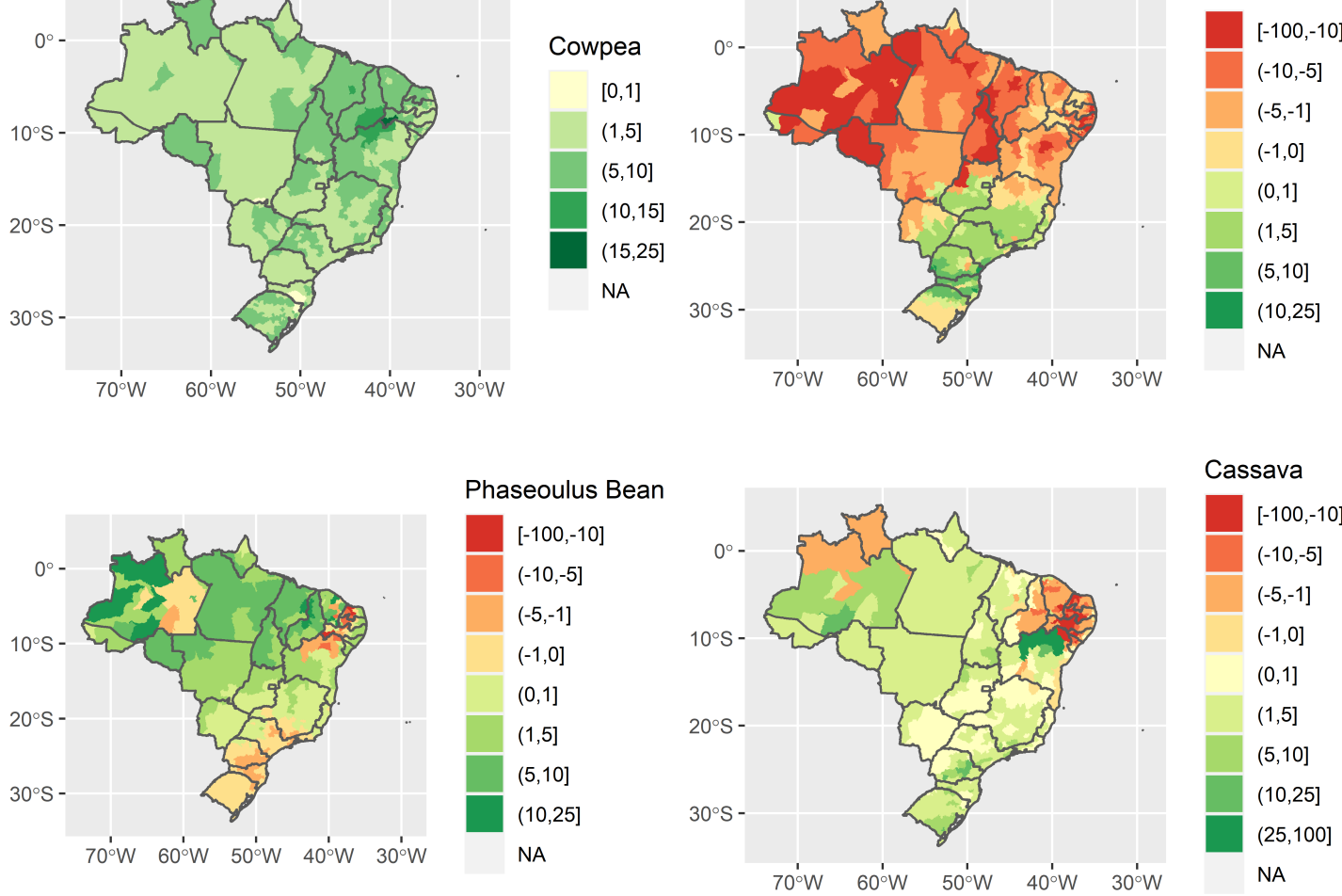

Notes: Changes in percentage points. Land Shares are our model's optimal land shares under each climate. Data source: Model estimates, GAEZ, 2006 Agricultural Census 
Table 12 - Predicted Changes in Agriculture Land Shares by Crops

\begin{tabular}{lccc}
\hline \hline Crops & $\begin{array}{c}\text { Predicted Land Share } \\
\text { in Baseline (\%) }\end{array}$ & $\begin{array}{c}\text { Change in Land Share } \\
\text { p.p. - A2 Climate }\end{array}$ & $\begin{array}{c}\text { Change in Land Share } \\
\text { p.p. - B1 Climate }\end{array}$ \\
\hline Soybean & 2.907 & 0.454 & 0.223 \\
Maize & 4.871 & 1.481 & 0.705 \\
Sugarcane & 2.744 & -0.180 & -0.085 \\
Dryland Rice & 3.421 & 1.490 & 0.984 \\
Cowpea & 4.729 & 1.176 & 0.700 \\
Coffee & 8.073 & -0.241 & -0.259 \\
Phaseoulus Bean & 6.209 & 1.956 & 0.940 \\
Cassava & 7.262 & 2.016 & 1.476 \\
Wheat & 1.592 & -0.886 & -0.652 \\
Cotton & 1.338 & 0.858 & 0.545 \\
Others & 56.853 & -9.399 & -6.106 \\
\hline
\end{tabular}

Notes: All results in this Table are based on our model's optimal farmers' land share allocation. Our aggregate predicted land share values are constructed by micro-regions land shares weighted by micro-region cultivated area. Changes in aggregate land shares are in percentage points, they are calculated as Optimal Land Share under Scenario Climate - Optimal Land Share under Baseline Climate. Source: Model estimates, GAEZ, 2006 Agricultural Census

interpret our results as signs of reallocation of land suitability that suggests actual spatial crop reallocation in future scenarios.

\subsection{Climate change effects on migration and agriculture}

In Table 13 we present the simulated effects of temperature changes in migration rates compared to a scenario where temperatures remained constant. We measure changes in migration rates in terms of percentage variation compared to a scenario where baseline climate was maintained. First line presents results where farmers reallocate their productions of crops according to the optimal choice for the new climate. Second line is an experiment in which farmers cannot alter the land shares of their crops, it is, they are locked with the optimal allocation for the baseline climate.

Surprisingly, migration rates are higher under scenario B1 compared to scenario A2. In Oliveira \& Pereda (2020), the same occurred under the exercise in which climate impacted only agricultural activity. As crop change presented very small effects on aggregate migration rates, it does not seem the case where greater changes in climate are triggering new crop allocations that are keeping people in the same micro-region via agricultural productivity. Two remaining possible explanations are that different changes in summer and winter temperatures under the two scenarios might be inducing this unexpected migration pattern, and that the agricultural productivity effect on housing rents might be having part in this phenomena. 

Table 13 - Simulated impact of climate change on aggregate migration rates

\begin{tabular}{lcc}
\hline \multicolumn{3}{c}{ Main specification } \\
$\Delta$ Migration Rate (\%) & B1 \\
\hline With Crop Change & 18.25 & 16.5 \\
Without Crop Change & 18.25 & 16.48 \\
\hline Note: Climate change scenarios for \\
2041-2070 period. The effects represent \\
changes relative to baseline climate, \\
which is the long-term average over \\
1961-1990. Baseline migration rate in our \\
main specification is 9.23\%. Simulations \\
use non-climate amenity levels of year \\
2010. Data source: Model estimates, \\
CPTEC/INPE, GAEZ, 2006 Agriculture \\
Census, and 1980-2010 Population Census.
\end{tabular}

In Table 14, we see the effect of climate change on agricultural employment. When farmers are not able to change crops, climate change has a greater negative impact on share of workers in the agriculture sector under scenario A2 than under scenario B1. The opposite phenomena is observed when farmers adopt the new optimal crop choice, with less workers in agriculture under scenario B1 than under A2. Adaptation has a greater impact on agriculture employment than the difference between the high and low emissions scenarios.

Tables 15 and 16 show the different effects of climate change over migration rates and share of workers employed in agriculture across Brazilian macro-regions. Again, crop change has small effects over migration rates. However, we now observe that the greatest shifts in share of employment in agriculture due to crop change come from the South macro-region.

\subsection{Climate change effects on welfare}

We also conduct an exercise of measuring the impact of climate change and agricultural adaptation on workers' welfare. Our welfare measure for workers is not simply their indirect utilities derived from living in location $k$ and working in sector $s$. Instead we consider workers' expected utility conditional on having chosen to live and work in the pair $(k, s) .{ }^{29}$ This means that the worker's welfare is not derived just from the indirect utility

\footnotetext{
29 The format and derivation of the worker's expected indirect utility is available in the Appendix A.2
} 
Table 14 - Simulated impact of climate change on agricultural shares

\begin{tabular}{|c|c|c|}
\hline \multirow{2}{*}{$\Delta$ Agric. Share (\%) } & \multicolumn{2}{|c|}{ Main specification } \\
\hline & B1 & $\mathrm{A} 2$ \\
\hline With Crop Change & -19.05 & -18.48 \\
\hline Without Crop Change & -20.66 & -20.89 \\
\hline \multicolumn{3}{|c|}{$\begin{array}{l}\text { Note: Climate change scenarios for } \\
\text { 2041-2070 period. The effects represent } \\
\text { changes relative to baseline climate, which } \\
\text { is the long-term average over 1961-1990. } \\
\text { Baseline agricultural share of employment } \\
\text { in our main specification is } 21.17 \% \text {. } \\
\text { Simulations use non-climate amenity levels } \\
\text { of year 2010. Data source: Model estimates, } \\
\text { CPTEC/INPE, GAEZ, 2006 Agriculture } \\
\text { Census, and 1980-2010 Population Census. }\end{array}$} \\
\hline
\end{tabular}

Table 15 - Simulated impact of climate change on macro-regions' migration rates

\begin{tabular}{lcccccccccc}
\hline \multirow{2}{*}{$\begin{array}{c}\text { Nig. Rate (\%) } \\
\end{array}$} & B1 & A2 & B1 & A2 & B1 & A2 & B1 & A2 & B1 & A2 \\
\hline W/ Crop Change & -0.79 & 22.75 & 98.83 & 78.24 & -6.16 & -7.82 & -2.39 & 1.74 & 5.32 & 11.22 \\
W/o Crop Change & -0.44 & 23.32 & 98.51 & 77.49 & -7.05 & -9.27 & -0.76 & 4.36 & 4.77 & 10.38 \\
\hline
\end{tabular}

Table 16 - Simulated impact of climate change on macro-regions' agricultural shares

\begin{tabular}{lcccccccccc}
\hline \multirow{2}{*}{$\Delta$ Agric. Share (\%) } & \multicolumn{2}{c}{ NO } & \multicolumn{2}{c}{ NE } & \multicolumn{2}{c}{ SE } & \multicolumn{2}{c}{ SO } & \multicolumn{2}{c}{ MW } \\
& B1 & A2 & B1 & A2 & B1 & A2 & B1 & A2 & B1 & A2 \\
\hline W/ Crop Change & -26.69 & -39.81 & -42.33 & -38.67 & -3.17 & -3.02 & 1.61 & 7.24 & -12.7 & -23.28 \\
W/o Crop Change & -28.7 & -42.93 & -43.52 & -39.87 & -3.52 & -3.43 & -2.53 & 0.17 & -13.12 & -24.2 \\
\hline
\end{tabular}

Note: Climate change scenarios for 2041-2070 period. The effects represent changes relative to baseline climate, which is the long-term average over 1961-1990. Simulations use non-climate amenity levels of year 2010. Baseline macro-regions' agriculture shares are respectively: $28.24 \%$, 30.79\%, 13.05\%, 23.39\%, 19.47\%. Data source: Model estimates, CPTEC/INPE, GAEZ, 2006 Agriculture Census, and 1980-2010 Population Census. 
Table 17 - Simulated impact of climate change on aggregate workers' welfare

\begin{tabular}{lcccc}
\hline \multirow{2}{*}{$\Delta$ Workers' Welfare (\%) } & \multicolumn{2}{c}{ Main specification } & \multicolumn{2}{c}{ Prohibitive mig. cost } \\
& B1 & A2 & B1 & A2 \\
\hline With Crop Change & -2.56 & 4.37 & -6.76 & -0.21 \\
Without Crop Change & -2.9 & 3.83 & -7.06 & -0.69 \\
\hline
\end{tabular}

Note: Climate change scenarios for 2041-2070 period. The effects represent changes relative to baseline climate, which is the long-term average over 1961-1990. Simulations use non-climate amenity levels of year 2010. Data source: Model estimates, CPTEC/INPE, GAEZ, 2006 Agriculture Census, and 1980-2010 Population Census.

Table 18 - Simulated impact of climate change on macro-regions' worker welfare

\begin{tabular}{|c|c|c|c|c|c|c|c|c|c|c|}
\hline \multirow{2}{*}{$\Delta$ Workers' Welfare (\%) } & \multicolumn{2}{|c|}{$\mathrm{NO}$} & \multicolumn{2}{|c|}{ NE } & \multicolumn{2}{|c|}{$\mathrm{SE}$} & \multicolumn{2}{|c|}{$\mathrm{SO}$} & \multicolumn{2}{|c|}{ MW } \\
\hline & B1 & $\mathrm{A} 2$ & B1 & $\mathrm{A} 2$ & B1 & $\mathrm{A} 2$ & B1 & $\mathrm{A} 2$ & B1 & $\mathrm{A} 2$ \\
\hline W/ Crop Change & -5.77 & -10.73 & -24.68 & -16.84 & -0.13 & 9.39 & -1.48 & 4.5 & -6.15 & -4.26 \\
\hline W/o Crop Change & -6.41 & -11.61 & -25.01 & -17.23 & -0.23 & 9.24 & -2.9 & 2.02 & -6.28 & -4.51 \\
\hline
\end{tabular}

Note: Climate change scenarios for 2041-2070 period. The effects represent changes relative to baseline climate, which is the long-term average over 1961-1990. Simulations use non-climate amenity levels of year 2010. Data source: Model estimates, CPTEC/INPE, GAEZ, 2006 Agriculture Census, and 1980-2010 Population Census.

enjoyed in her location, but also from the indirect utilities of other locations although discounted by a migration cost.

In Table 17 we can observe the impact of climate change on workers' welfare measured by our model. Our welfare measure indicate a lower worker aggregate welfare under B1 scenario than under A2. Crop change increases workers' welfare under both scenarios. Our exercise to measure welfare under prohibitive migration costs suggests that migration has an important role in off-setting the negative effects of climate change on individuals.

In Table 18 we display the welfare impacts of climate change on workers by macroregion. By this exercise, we see that the positive welfare impacts of climate under the A2 scenario are driven by the results from the South and Southeast macro-regions. The Northeast macro-region suffers from the most negative impacts from climate change under both scenarios. The second most negatively affected region in terms of workers' welfare depends on scenario and if crop change is adopted: the North macro-region occupies this second place under scenario A2 and under the B1 scenario when there is no crop change, while the Midwest macro-region is worse under scenario B1 with crop change. These 
results suggests that climate change will have an impact on deepening inequalities among macro-regions in Brazil as the most developed regions are less negatively affected - or even positively affected - by this phenomena when compared to the least developed ones. 


\section{Final Remarks}

In this paper, we analyze how climate change is expected to affect agricultural crop production patterns, internal migration, and the distribution of the labor force in Brazil using a single approach. We advance on the existing and related literature - Costinot, Donaldson \& Smith (2016) and Oliveira \& Pereda (2020) that investigate climate-induced crop change and internal migration - by using a more extensive set of crops for adaptation and a more refined geographic level for migration.

We propose and estimate a spatial equilibrium model with costly migration where climate affects workers' locational choice and farmers' crop choice. Climate can directly affect workers' location decisions through a location-amenity channel and agricultural productivity, affecting agricultural wages and housing rental prices. Farmer's ability to reallocate their inputs towards new and more productive crops impacts agricultural productivity. Furthermore, general equilibrium effects on labor and housing markets play a role in workers' spatial distribution and welfare.

Our results suggest that there will be a spatial redistribution of crop productions under future climatic conditions that helps mitigate some of the effects of climate change on agricultural productivity and agriculture share of employment. However, agriculture adaptation will likely have minimal effects on aggregate micro-region migration. In terms of regional effects, the Northeast macro-region will be the most affected under any scenario with more significant increases in out-migration rates, decreases in agriculture share of employment, and negative impacts on workers' welfare. The South macro-region is where we expect that crop change will impact the most agricultural share of employment. Potential welfare gains for workers are primarily concentrated in the Southeast macro-region, which is already the more prosperous and most populated region in Brazil. Hence, our results map the regions with higher potential for agriculture adaptation and reaffirm the potential deepening of the existing north-south inequality in Brazil diagnosed in Oliveira \& Pereda (2020). Our results may help guide public policies by identifying the more vulnerable populations and the regions where most gains from agricultural adaptation may come from. 


\section{Reference List}

AVILA, A. F. D.; EVENSON, R. E. Total factor productivity growth in agriculture: the role of technological capital. Handbook of agricultural economics, Elsevier, v. 4, p. 3769-3822, 2010.

BARRIOS, S.; BERTINELLI, L.; STROBL, E. Climatic change and rural-urban migration: The case of sub-saharan africa. Journal of Urban Economics, Elsevier, v. 60, n. 3, p. 357-371, 2006.

BARTIK, T. J. Who benefits from state and local economic development policies? WE Upjohn Institute for Employment Research, 1991.

BERRY, S.; LEVINSOHN, J.; PAKES, A. Differentiated products demand systems from a combination of micro and macro data: The new car market. Journal of political Economy, The University of Chicago Press, v. 112, n. 1, p. 68-105, 2004.

BUSTOS, P.; CAPRETTINI, B.; PONTICELLI, J. Agricultural productivity and structural transformation: Evidence from brazil. American Economic Review, v. 106, n. 6, p. $1320-65,2016$.

CAI, R. et al. Climate variability and international migration: The importance of the agricultural linkage. Journal of Environmental Economics and Management, Elsevier, v. 79, p. 135-151, 2016.

COSTINOT, A.; DONALDSON, D.; SMITH, C. Evolving comparative advantage and the impact of climate change in agricultural markets: Evidence from 1.7 million fields around the world. Journal of Political Economy, University of Chicago Press Chicago, IL, v. 124, n. 1, p. 205-248, 2016.

CUI, X. Climate change and adaptation in agriculture: Evidence from us cropping patterns. Journal of Environmental Economics and Management, Elsevier, v. 101, p. 102306, 2020.

DEPAULA, G.; MENDELSOHN, R. Development and the impact of climate change on energy demand: evidence from brazil. Climate Change Economics, World Scientific, v. 1, n. 03, p. 187-208, 2010.

DIAMOND, R. The determinants and welfare implications of us workers' diverging location choices by skill: 1980-2000. American Economic Review, v. 106, n. 3, p. 479-524, 2016.

DONALDSON, D.; HORNBECK, R. Railroads and american economic growth: A "market access" approach. The Quarterly Journal of Economics, MIT Press, v. 131, n. 2, p. 799-858, 2016.

DRABO, A.; MBAYE, L. M. Natural disasters, migration and education: an empirical analysis in developing countries. Environment and Development Economics, JSTOR, v. 20, n. 6, p. 767-796, 2015. 
EATON, J.; KORTUM, S. Technology, geography, and trade. Econometrica, Wiley Online Library, v. 70, n. 5, p. 1741-1779, 2002.

FENG, S.; OPPENHEIMER, M.; SCHLENKER, W. Climate change, crop yields, and internal migration in the United States. [S.1.], 2012.

FINDLEY, S. E. Does drought increase migration? a study of migration from rural mali during the 1983-1985 drought. International Migration Review, SAGE Publications Sage CA: Los Angeles, CA, v. 28, n. 3, p. 539-553, 1994.

IIASA, F. Global agro-ecological zones (gaez v3. 0). IIASA, Laxenburg, Austria and FAO, Rome, Italy, 2012.

MANSUR, E. T.; MENDELSOHN, R.; MORRISON, W. Climate change adaptation: A study of fuel choice and consumption in the us energy sector. Journal of Environmental Economics and Management, v. 55, n. 2, p. 175-193, 2008.

MARCHIORI, L.; MAYSTADT, J.-F.; SCHUMACHER, I. The impact of weather anomalies on migration in sub-saharan africa. Journal of Environmental Economics and Management, Elsevier, v. 63, n. 3, p. 355-374, 2012.

MARCHIORI, L.; SCHUMACHER, I. When nature rebels: international migration, climate change, and inequality. Journal of Population Economics, Springer, v. 24, n. 2, p. 569-600, 2011.

MONIRUZZAMAN, S. Crop choice as climate change adaptation: Evidence from bangladesh. Ecological Economics, Elsevier, v. 118, p. 90-98, 2015.

MORTEN, M.; OLIVEIRA, J. The effects of roads on trade and migration: Evidence from a planned capital city. NBER Working Paper. Cambridge, MA, USA: National Bureau of Economic Research, 2016.

NEHRING, R. Yield of dreams: Marching west and the politics of scientific knowledge in the brazilian agricultural research corporation (embrapa). Geoforum, Elsevier, v. 77, p. 206-217, 2016.

NETO, C. Alvares da S. C. Portos brasileiros: Área de influência, ranking, porte e os principais produtos movimentados. Texto Para Discussão No, 2006.

OLIVEIRA, J.; PALIALOL, B.; PEREDA, P. Do temperature shocks affect non-agriculture wages in brazil? evidence from individual-level panel data. Environment and Development Economics, Cambridge University Press, p. 1-16, 2021.

OLIVEIRA, J.; PEREDA, P. The impact of climate change on internal migration in brazil. Journal of Environmental Economics and Management, Elsevier, v. 103, p. 102340, 2020.

SALDAÑA-ZORRILLA, S. O.; SANDBERG, K. Impact of climate-related disasters on human migration in mexico: a spatial model. Climatic change, Springer, v. 96, n. 1, p. 97-118, 2009.

SEO, S. N.; MENDELSOHN, R. An analysis of crop choice: Adapting to climate change in south american farms. Ecological economics, Elsevier, v. 67, n. 1, p. 109-116, 2008. 
SINHA, P.; CAULKINS, M. L.; CROPPER, M. L. Household location decisions and the value of climate amenities. Journal of Environmental Economics and Management, Elsevier, v. 92, p. 608-637, 2018.

SOTELO, S. Domestic trade frictions and agriculture. Journal of Political Economy, The University of Chicago Press Chicago, IL, v. 128, n. 7, p. 2690-2738, 2020.

TIMMINS, C. If you cannot take the heat, get out of the cerrado... recovering the equilibrium amenity cost of nonmarginal climate change in brazil. Journal of Regional Science, Wiley Online Library, v. 47, n. 1, p. 1-25, 2007.

WANG, J. et al. How chinese farmers change crop choice to adapt to climate change. Climate Change Economics, World Scientific, v. 1, n. 03, p. 167-185, 2010. 


\section{Appendix A - Model}

\section{A.1 Deriving Migration Probabilities}

Given the distributional assumption that $P\left(\vartheta_{n k s t} \leq x\right)=\exp \left\{-x^{-\sigma}\right\}$, the probability that locality-sector pair $(k, s)$ maximizes the indirect utility is

$$
P\left(V_{k s t} \exp \left\{-\mu_{j k}\right\} \vartheta_{n k s t} \geq V_{l q t} \exp \left\{-\mu_{j l}\right\} \vartheta_{n l q t} \forall l \neq k, \forall q \neq s\right)
$$

We define the random variables $W=V_{k s t} \exp \left\{-\mu_{j k}\right\} \vartheta_{n k s t}$ and $M=\max _{(l, q) \neq(k, s)} V_{l q t} \exp \left\{-\mu_{j l}\right\} \vartheta_{n l q t}$.

$$
\begin{aligned}
F_{W}(x) & =P\left(V_{k s t} \exp \left\{-\mu_{j k}\right\} \vartheta_{n k s t} \leq x\right) \\
& =P\left(\vartheta_{n k s t} \leq \frac{x}{V_{k s t} \exp \left\{-\mu_{j k}\right\}}\right) \\
& =\exp \left\{-\left(\frac{x}{V_{k s t} \exp \left\{-\mu_{j k}\right\}}\right)^{-\sigma}\right\}
\end{aligned}
$$

Hence $W$ has a Fréchet distribution with $E[W]=V_{k s t} \exp \left\{-\mu_{j k}\right\} \Gamma\left(1-\frac{1}{\sigma}\right)=a_{W}$. Furthermore:

$$
\begin{aligned}
F_{M}(x) & =P\left(\max _{(l, q) \neq(k, s)} V_{l q t} \exp \left\{-\mu_{j l}\right\} \vartheta_{n l q t} \leq x\right) \\
& =\prod_{(l, q) \neq(k, s)} P\left(V_{l q t} \exp \left\{-\mu_{j l}\right\} \vartheta_{n l q t} \leq x\right) \\
& =\prod_{(l, q) \neq(k, s)} P\left(\vartheta_{n l q t} \leq \frac{x}{V_{l q t} \exp \left\{-\mu_{j l}\right\}}\right) \\
& =\exp \left\{-\sum_{l \neq q} \sum_{q \neq s}\left(\frac{x}{V_{l q t} \exp \left\{-\mu_{j l}\right\}}\right)^{-\sigma}\right\} \\
& =\exp \left\{-\left(\frac{x}{\left(\sum_{l \neq q} \sum_{q \neq s}\left(V_{l q t} \exp \left\{-\mu_{j l}\right\}\right)^{\sigma}\right)^{1 / \sigma}},\right)^{-\sigma}\right\}
\end{aligned}
$$

which is a Fréchet distribution with $E[M]=\left[\sum_{l \neq q} \sum_{q \neq s}\left(V_{l q t} \exp \left\{-\mu_{j l}\right\}\right)^{\sigma}\right]^{\frac{1}{\sigma}} \Gamma\left(1-\frac{1}{\sigma}\right)=a_{M}$. 
Let $y=\exp \left\{-\left(\frac{x}{\left(a_{W}^{\sigma}+a_{M}^{\sigma}\right)^{1 / \sigma}}\right)^{-\sigma}\right\}$. We can derive $\pi_{j k s t}$ as:

$$
\begin{aligned}
\pi_{j k s t} & =\int_{0}^{\infty}\left[1-e^{-\left(x / a_{W}\right)^{-\sigma}}\right]\left(\frac{\sigma}{a_{M}}\right)\left(\frac{x}{a_{M}}\right)^{-\sigma-1} e^{-\left(x / a_{M}\right)^{-\sigma}} \partial x \\
& =1-\int_{0}^{\infty} \exp \left\{\left(\frac{x}{\left(a_{W}^{\sigma}+a_{M}^{\sigma}\right)^{\frac{1}{\sigma}}}\right)^{-\sigma}\right\} \sigma a_{M}^{\sigma} x^{-\sigma-1} \partial x \\
& =1-\int_{0}^{1} \frac{a_{M}^{\sigma}}{a_{W}^{\sigma}+a_{M}^{\sigma}} \partial y \\
& =\frac{a_{W}^{\sigma}}{a_{W}^{\sigma}+a_{M}^{\sigma}} \\
& =\frac{\left(V_{k s t} \exp \left\{-\mu_{j k}\right)^{\sigma}\right\}}{\sum_{l=1}^{J} \sum_{q \in\{r, u\}}\left(V_{l q t} \exp \left\{-\mu_{j l}\right\}\right)^{\sigma}} .
\end{aligned}
$$

\section{A.2 Workers' Welfare - Expected Utility}

To quantify the welfare impacts of climate change and of agricultural adaptation, we need to compute the expected utilities conditional on location choice, $E[V n j k s \mid$ choose $k$ and $s]$. When an individual chooses a locality $k$ and a sector $s$, this means that $(k, s)=$ $\arg \max _{l, q}\left\{V_{n j l q}\right\}$. Then, $E[V n j k s \mid$ choose $k$ and $s]=E\left[\max _{l, q}\left\{V_{n j l q}\right\}\right]$. Moreover, from our distributional assumptions:

$$
\begin{aligned}
P\left(\max _{l, q}\left\{V_{n j l q}\right\} \leq x\right) & =\prod_{l=1}^{J} \prod_{q \in r, u} P\left(V_{l q} e^{-\mu_{j l}} \vartheta_{n l q} \leq x\right) \\
& =\prod_{l=1}^{J} \prod_{q \in r, u} P\left(\vartheta_{n l q} \leq \frac{x}{V_{l q} e^{-\mu_{j l}}}\right) \\
& =\prod_{l=1}^{J} \prod_{q \in r, u}\left\{-\left(\frac{x}{V_{l q} e^{-\mu_{j l}}}\right)^{-\sigma}\right\} \\
& =\exp \left\{-\sum_{l=1}^{J} \sum_{s \in\{r, u\}}\left(\frac{x}{V_{l q} e^{-\mu_{j l}}}\right)^{-\sigma}\right\} \\
& =\exp \left\{\left[\frac{x}{\left(\sum_{l=1}^{J} \sum_{s \in\{r, u\}}\left(V_{l q} e^{-\mu_{j l}}\right)^{\sigma}\right)^{1 / \sigma}}\right]^{-\sigma}\right\} .
\end{aligned}
$$

Hence, $E\left[\max _{l, q}\left\{V_{n j l q}\right\}\right]=\left[\sum_{l=1}^{J} \sum_{s \in\{r, u\}}\left(V_{l q} e^{-\mu_{j l} l}\right)^{\sigma}\right]^{1 / \sigma} \Gamma\left(1-\frac{1}{\sigma}\right)$. 


\section{A.3 Land Suitability Expected Value}

The distribution of $A_{k r t}^{m}(\omega)$ is:

$$
\begin{aligned}
F_{k r t, m}(t) & =\exp \left\{-\gamma\left(\frac{t}{A_{k r t}^{m}}\right)^{-\theta}\right\} \\
& =\exp \left\{-\left(\frac{t}{\gamma^{\frac{1}{\theta}} A_{k r t}^{m}}\right)^{-\theta}\right\}
\end{aligned}
$$

Using the properties of the Fréchet distribution, the unconditional expectation of $A_{k r t}^{m}(\omega)$ is:

$$
\begin{aligned}
E\left[A_{k r t}^{m}(\omega)\right] & =\gamma^{\frac{1}{\theta}} A_{k r t}^{m} \Gamma\left(1-\frac{1}{\theta}\right) \\
& =A_{k r t}^{m}
\end{aligned}
$$

\section{A.4 Profit Maximization}

The representative agricultural firm in locality $k$ hires labor and rents land. The farmer decides how to allocate plots of land across crops and chooses the amount of labor employed in each plot. Consider $\Omega_{k}$ as the set of plots that are allocated to agriculture in locality $k$. The producer's problem is to choose $\left\{N_{k r}^{m}(\omega), L_{k r}^{m}(\omega), \omega \in \Omega_{k}, \forall k\right\}$ to maximize profits:

$$
\max \sum_{m=1}^{M} p_{k r t}^{m} Q_{k r t}^{m}-\int_{\Omega_{k}} \sum_{m=1}^{M}\left[w_{k r t} N_{k r t}^{m}(\omega)+R_{k t} L_{k r t}^{m}(\omega)\right] \partial \omega
$$

where, for all $k$, total output of crop $m$ is:

$$
Q_{k r t}^{m}=\int_{\Omega_{k}} A_{k r t}^{m}(\omega)\left[N_{k r t}^{m}(\omega)\right]^{\alpha_{r}}\left[L_{k r t}^{m}(\omega)\right]^{1-\alpha_{r}} \partial \omega
$$

An equivalent problem for the agricultural producer is to maximize the profits obtained in each plot $\omega$ and then add up the profits across the plots. The profits in a plot $\omega$ are:

$$
\sum_{m=1}^{M} p_{k r t}^{m} A_{k r t}^{m}(\omega)\left[N_{k r t}^{m}(\omega)\right]^{\alpha_{r}}\left[L_{k r t}^{m}(\omega)\right]^{1-\alpha_{r}}-w_{k r t} N_{k r t}^{m}(\omega)-R_{k t} L_{k r t}^{m}(\omega) .
$$

Following Sotelo (2020), we can characterize the farmer's problem in term of the unit cost function of producing each good in a given plot $\omega$. Consider $\Omega_{k}^{m}$ as the set of plots in locality $k$ allocated for growing crop $m$. Suppose that $\omega \in \Omega_{k}^{m}$, such that $L_{k r t}^{m}(\omega)>0$. The cost minimization problem when producing this crop $m$ is to choose $N_{k r t}^{m}(\omega)$ and $L_{k r t}^{m}(\omega)$ such that: 


$$
\begin{aligned}
& \min w_{k r t} N_{k r t}^{m}(\omega)+R_{k t} L_{k r t}^{m}(\omega) \\
& \text { s.t. } A_{k r t}^{m}(\omega)\left[N_{k r t}^{m}(\omega)\right]^{\alpha_{r}}\left[L_{k r t}^{m}(\omega)\right]^{1-\alpha_{r}} \geq \bar{Q}_{k r t}^{m} .
\end{aligned}
$$

The solution to this problem will consist on a cost function and conditional demands for inputs. The Lagrangean to this problem is:

$$
\mathcal{L}=w_{k r t} N_{k r t}^{m}(\omega)+R_{k t} L_{k r t}^{m}(\omega)-\mu\left[A_{k r t}^{m}(\omega)\left[N_{k r t}^{m}(\omega)\right]^{\alpha_{r}}\left[L_{k r t}^{m}(\omega)\right]^{1-\alpha_{r}}-\bar{Q}_{k r t}^{m}\right] .
$$

Which yields the following first order conditions:

$$
\begin{aligned}
& {\left[N_{k r t}^{m}(\omega)\right]: w_{k r t}=\mu \alpha_{r} A_{k r t}^{m}(\omega)\left[N_{k r t}^{m}(\omega)\right]^{-\left(1-\alpha_{r}\right)}\left[L_{k r t}^{m}(\omega)\right]^{1-\alpha_{r}},} \\
& {\left[L_{k r t}^{m}(\omega)\right]: R_{k t}=\mu\left(1-\alpha_{r}\right) A_{k r t}^{m}(\omega)\left[N_{k r t}^{m}(\omega)\right]^{\alpha_{r}}\left[L_{k r t}^{m}(\omega)\right]^{-\alpha_{r}} .}
\end{aligned}
$$

Using the production function from Equation 4 and rearranging the first order conditions, we reach the conditional input demands:

$$
\begin{gathered}
N_{k r t}^{m}(\omega)=\frac{\mu \alpha_{r} Q_{k r t}^{m}(\omega)}{w_{k r t}}, \\
L_{k r t}^{m}(\omega)=\frac{\mu\left(1-\alpha_{r}\right) Q_{k r t}^{m}(\omega)}{R_{k t}} .
\end{gathered}
$$

Now, note that $\mu$ is the marginal cost. We can substitute the input demands in the production function to find the cost function.

$$
Q_{k r t}^{m}(\omega)=A_{k r t}^{m}(\omega)\left[\frac{c_{k r t}^{m}(\omega) \alpha_{r} Q_{k r t}^{m}(\omega)}{w_{k r t}}\right]^{\alpha_{r}}\left[\frac{c_{k r t}^{m}(\omega)\left(1-\alpha_{r}\right) Q_{k r t}^{m}(\omega)}{R_{k t}}\right]^{\left(1-\alpha_{r}\right)}
$$

Rearranging the equation we find the marginal cost of producing crop $m$ in plot $\omega$ :

$$
\begin{aligned}
c_{k r t}^{m}(\omega) & =\alpha_{r}^{-\alpha_{r}}\left(1-\alpha_{r}\right)^{\left(1-\alpha_{r}\right)} \frac{w_{k r t}^{\alpha_{r}} R_{k r t}^{1-\alpha_{r}}}{A_{k r t}^{m}(\omega)} \\
& =\bar{c} \frac{w_{k r t}^{\alpha_{r}} R_{k r t}^{1-\alpha_{r}}}{A_{k r t}^{m}(\omega)}
\end{aligned}
$$

where $\bar{c}=\alpha_{r}^{-\alpha_{r}}\left(1-\alpha_{r}\right)^{\left(1-\alpha_{r}\right)}$

Also, through the conditional input demands, we have:

$$
\frac{w_{k r t}}{R_{k t}}=\frac{\alpha_{r}}{1-\alpha_{r}} \frac{L_{k r t}^{m}(\omega)}{N_{k r t}^{m}(\omega)}
$$


Because, within a locality $k$, agricultural wage and land rent are fixed across crops and plots, and cost shares are constants, this means that the land-labor ratio will be the same across every $\omega \in \Omega_{k}^{m}$ and every produced crop in the locality. Consequently, will also hold:

$$
\frac{w_{k r t}}{R_{k t}}=\frac{\alpha_{r}}{1-\alpha_{r}} \frac{L_{k r t}}{N_{k r t}},
$$

where $N_{k r t}$ is the total amount of labor employed in agriculture in locality $k$ and $L_{k r t}$ is the total area used to grow crops in locality $k$. Also, this will imply that, within a locality, the share of land used to grow a crop $m$ and the share of labor to grow the same crop will be the same:

$$
\frac{L_{k r t}^{m}}{N_{k r t}^{m}}=\frac{L_{k r t}}{N_{k r t}} \forall m \rightarrow \frac{N_{k r t}^{m}}{N_{k r t}}=\frac{L_{k r t}^{m}}{L_{k r t}} \forall m
$$

\section{A.5 Implications of Profit Maximization}

Once we have characterized the marginal cost function, we can return to the farmer's problem. At the crop-plot level, the farmer will chooses $Q_{k r t}^{m}(\omega)$ that maximizes profit:

$$
\max p_{k r t}^{m} Q_{k r t}^{m}(\omega)-c_{k r t}^{m}(\omega) Q_{k r t}^{m}(\omega) \text {. }
$$

Because technology has constant returns to scale, it is not possible to determine an optimal output by solving this problem. Instead, all we have is a condition that must be held at an optimum: $p_{k r t}^{m} \leq c_{k r t}^{m}(\omega)$, with equality when $Q_{k r t}^{m}(\omega)>0$. Thus, if $Q_{k r t}^{m}(\omega)>0$, we can derive the equilibrium between gains and costs of an optimal increase in inputs:

$$
p_{k r t}^{m} A_{k r t}^{m}(\omega)=\bar{c} w_{k r t}^{\alpha_{r}} R_{k r t}^{1-\alpha_{r}} .
$$

The costs associated with an optimal increase in inputs are invariant across crops within locality $k$.

We call $c_{k r t}(\omega)=\bar{c} w_{k r t}^{\alpha_{r}} R_{k r t}^{1-\alpha_{r}}$ the marginal cost of an optimal increase in inputs in plot $\omega \in \Omega_{k}$. As $c_{k r t}(\omega)$ is invariant across crops, if a crop $m$ is being produced in plot $\omega$ and the farmer knows the productivities associated with all crops, a profit maximization behavior ensures that crop $m$ is the one that would produce maximum returns in that plot. Therefore:

$$
\forall \omega \in \Omega_{k}: c_{k r t}(\omega)=\max _{m}\left\{p_{k r t}^{m} A_{k r t}^{m}(\omega)\right\}
$$

As each plot of land is allocated to the crop which gives the highest returns, and there is a continuum of plots in each locality $k$, the share of land occupied by each crop will be:

$$
\eta_{k r t}^{m}=\operatorname{Pr}\left(m=\arg \max _{n} p_{k r t}^{n} A_{k r t}^{n}(\omega)\right)
$$


Then, given our distributional assumptions about, $A_{k r t}^{n}(\omega)$ :

$$
\eta_{k r t}^{m}=\frac{\left(p_{k r t}^{m} A_{k r t}^{m}\right)^{\theta}}{\sum_{l=1}^{M}\left(p_{k r t}^{l} A_{k r t}^{l}\right)^{\theta}}
$$

Proof: Given the distributional assumption, $P\left(A_{k r t}^{m}(\omega) \leq a^{m}\right)=\exp \left\{-\gamma\left(\frac{a^{m}}{A_{k r t}^{m}}\right)^{-\theta}\right\}$, with $E\left[A_{k r t}^{m}(\omega)\right]=A_{k r t}^{m}$. The probability that crop $m$ maximizes revenue at plot $\omega$ can be described as: $P\left(p_{k r t}^{m} A_{k r t}^{m}(\omega) \geq \max _{n \neq m}\left\{p_{k r t}^{n} A_{k r t}^{n}(\omega)\right\}\right)$. We define the random variables $W=p_{k r t}^{m} A_{k r t}^{m}(\omega)$ and $M=\max _{n \neq m}\left\{p_{k r t}^{n} A_{k r t}^{n}(\omega)\right\}$. Then,

$$
\begin{aligned}
F_{W}(x) & =P\left(p_{k r t}^{m} A_{k r t}^{m}(\omega) \leq x\right) \\
& =P\left(A_{k r t}^{m}(\omega) \leq \frac{x}{p_{k r t}^{m}}\right) \\
& =\exp \left\{-\gamma\left(\frac{x}{p_{k r t}^{m} A_{k r t}^{m}}\right)^{-\theta}\right\} \\
& =\exp \left\{-\left(\frac{x}{\gamma^{\frac{1}{\theta}} p_{k r t}^{m} A_{k r t}^{m}}\right)^{-\theta}\right\},
\end{aligned}
$$

which is a Fréchet distribution with $E[W]=p_{k r t}^{m} A_{k r t}^{m}=a^{W}$. Furthermore,

$$
\begin{aligned}
& F_{M}(x)=P\left(\max _{n \neq m}\left\{p_{k r t}^{n} A_{k r t}^{n}(\omega)\right\} \leq x\right) \\
& =\prod_{n \neq m} P\left(p_{k r t}^{n} A_{k r t}^{n} \leq x\right) \\
& =\exp \left\{-\gamma \sum_{n \neq m}\left(\frac{x}{p_{k r t}^{n} A_{k r t}^{n}}\right)^{-\theta}\right\} \\
& =\exp \left\{-\gamma x^{-\theta} \sum_{n \neq m}\left(p_{k r t}^{n} A_{k r t}^{n}\right)^{\theta}\right\} \\
& =\exp \left\{-\gamma x^{-\theta}\left[\left(\sum_{n \neq m}\left(p_{k r t}^{n} A_{k r t}^{n}\right)^{\theta}\right)^{-\frac{1}{\theta}}\right]^{-\theta}\right\}
\end{aligned}
$$

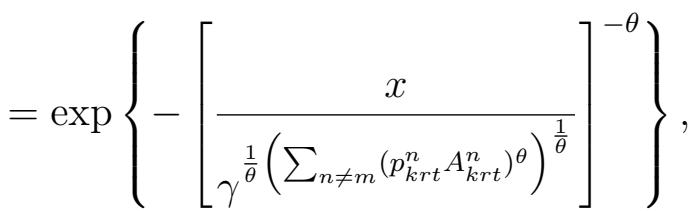

which is a Fréchet distribution with $E[M]=\left[\sum_{n \neq m}\left(p_{k r t}^{n} A_{k r t}^{n}\right)^{\theta}\right]^{\frac{1}{\theta}}=a^{M}$. 


$$
\begin{aligned}
& \text { Let } y=\exp \left\{-\gamma\left(\frac{x}{\left(a_{W}^{\theta}+a_{M}^{\theta}\right)^{\frac{1}{\theta}}}\right)^{-\theta}\right\} \text {. We can derive } \eta_{k r t}^{m} \text { as: } \\
& \qquad \begin{aligned}
\eta_{k r t}^{m} & =\int_{0}^{\infty}\left[1-e^{-\gamma\left(x / a_{W}\right)^{-\theta}}\right]\left(\frac{\theta \gamma}{a_{M}}\right)\left(\frac{x}{a_{M}}\right)^{-\theta-1} e^{-\gamma\left(x / a_{M}\right)^{-\theta} \partial x} \\
& =1-\int_{0}^{\infty} \exp \left\{-\gamma\left(\frac{x}{\left(a_{W}^{\theta}+a_{M}^{\theta}\right)^{\frac{1}{\theta}}}\right)^{-\theta}\right\} \theta \gamma\left(a_{M}\right)^{\theta} x^{-\theta-1} \partial x \\
& =1-\int_{0}^{1} \frac{a_{M}^{\theta}}{a_{W}^{\theta}+a_{M}^{\theta}} \partial y \\
& =1-\frac{a_{M}^{\theta}}{a_{W}^{\theta}+a_{M}^{\theta}} \\
& =\frac{a_{W}^{\theta}}{a_{W}^{\theta}+a_{M}^{\theta}} \\
& =\frac{\left(p_{k r t}^{m} A_{k r t}^{m}\right)^{\theta}}{\sum_{l=1}^{M}\left(p_{k r t}^{n} A_{k r t}^{n}\right)^{\theta}} .
\end{aligned}
\end{aligned}
$$

\section{A.6 Conditional Distribution of Land Quality}

To match the model to data, we must characterize the distribution of the land suitability conditional on $\omega \in \Omega_{k}^{m}$. Defining:

$$
G_{k r t}^{m}(x)=P\left[A_{k r t}^{m}(\omega) \leq x \mid p_{k r t}^{m} A_{k r t}^{m}(\omega)=\max _{n} p_{k r t}^{n} A_{k r t}^{n}(\omega)\right] .
$$

We can rearrange the probability function: 


$$
\begin{aligned}
G_{k r t}^{m}(x) & =\frac{1}{\eta_{k r t}^{m}} P\left[\frac{p_{k r t}^{n}}{p_{k r t}^{m}} A_{k r t}^{n}(\omega) \leq A_{k r t}^{m}(\omega) \leq x \forall n\right] \\
& =\frac{1}{\eta_{k r t}^{m}} \int_{0}^{x} \prod_{n \neq m} P\left[\frac{p_{k r t}^{n}}{p_{k r t}^{m}} A_{k r t}^{n}(\omega) \leq v\right] f_{k r t}^{m}(v) \partial v \\
& =\frac{1}{\eta_{k r t}^{m}} \int_{0}^{x} \prod_{n \neq m} \exp \left\{-\gamma\left(\frac{v}{\frac{p_{k r t}^{n}}{p_{k r t}^{m}} A_{k r t}^{n}}\right)^{-t h e t a}\right\} \exp \left\{-\gamma\left(\frac{v}{A_{k r t}^{m}}\right)^{-\theta}\right\} \theta \gamma\left(A_{k r t}^{m}\right)^{\theta} v^{-\theta-1} \partial v \\
& =\frac{1}{\eta_{k r t}^{m}} \int_{0}^{x} \exp \left\{-\gamma\left(p_{k r t}^{m} v\right)^{-\theta} \sum_{n=1}^{M}\left(p_{k r t}^{n} A_{k r t}^{n}\right)^{\theta}\right\} \theta \gamma\left(A_{k r t}^{m}\right)^{\theta} v^{-\theta-1} \partial v \\
& =\int_{0}^{x} \exp \left\{-\gamma\left(p_{k r t}^{m} v\right)^{-\theta} \sum_{n=1}^{M}\left(p_{k r t}^{n} A_{k r t}^{n}\right)^{\theta}\right\}\left(\frac{\sum_{n=1}^{M}\left(p_{k r t}^{n} A_{k r t}^{n}\right)^{\theta}}{\left(p_{k r t}^{m} A_{k r t}^{m}\right)^{\theta}}\right) \theta \gamma\left(A_{k r t}^{m}\right)^{\theta} v^{-\theta-1} \partial v \\
& =\int_{0}^{x} \exp \left\{-\gamma\left(p_{k r t}^{m} v\right)^{-\theta} \sum_{n=1}^{M}\left(p_{k r t}^{n} A_{k r t}^{n}\right)^{\theta}\right\}\left(\sum_{n=1}^{M}\left(p_{k r t}^{n} A_{k r t}^{n}\right)^{\theta}\right) \theta \gamma\left(p_{k r t}^{m}\right)^{-\theta} v^{-\theta-1} \partial v \\
& =\exp \left\{-\gamma\left(p_{k r t}^{m} x\right)^{-\theta} \sum_{n=1}^{M}\left(p_{k r t}^{n} A_{k r t}^{n}\right)^{\theta}\right\} \\
& =\exp \left\{-\gamma\left(\frac{x}{\frac{\left(\sum_{n=1}^{M}\left(p_{k r}^{n} A_{k r t}^{n}\right)^{\theta}\right)^{\frac{1}{\theta}}}{p_{k r t}}}\right)^{-\theta}\right\} .
\end{aligned}
$$

Thus:

$$
E\left[A_{k r t}^{m}(\omega) \mid m=\arg \max _{n}\left\{p_{k r t}^{n} A_{k r t}^{n}(\omega)\right\}\right]=\frac{\left(\sum_{n=1}^{M}\left(p_{k r t}^{n} A_{k r t}^{n}\right)^{\theta}\right)^{\frac{1}{\theta}}}{p_{k r t}^{m}}=\left(\eta_{k r t}^{m}\right)^{-\frac{1}{\theta}} A_{k r t}^{m}
$$

\section{A.7 Agricultural Wage}

At last, we return to the agricultural firm profit maximization problem to obtain a last equation for the agricultural wage. The firm profit can be presented as:

$$
\begin{aligned}
\Pi_{k r t} & =\sum_{m=1}^{M}\left\{\int_{\Omega_{k}} p_{k r t}^{m} A_{k r t}^{m}(\omega)\left[N_{k r t}^{m}(\omega)\right]^{\alpha_{r}}\left[L_{k r t}^{m}(\omega)\right]^{1-\alpha_{r}} \partial \omega\right\}-w_{k r t} N_{k r t}-R_{k r t} L_{k r t} \\
& =\sum_{m=1}^{M}\left\{p_{k r t}^{m} E\left[A_{k r t}^{m}(\omega) \mid m=\arg \max _{n} p_{k r t}^{n} A_{k r t}^{n}(\omega)\right]\left(N_{k r t}^{m}\right)^{\alpha_{r}}\left(L_{k r t}^{m}\right)^{1-\alpha_{r}}\right\}-w_{k r t} N_{k r t}-R_{k r t} L_{k r t} \\
& =\sum_{m=1}^{M}\left\{p_{k r t}^{m}\left(\eta_{k r t}^{m}\right)^{-\frac{1}{\theta}} A_{k r t}^{m}\left(N_{k r t}^{m}\right)^{\alpha_{r}}\left(L_{k r t}^{m}\right)^{1-\alpha_{r}}\right\}-w_{k r t} N_{k r t}-R_{k r t} L_{k r t} .
\end{aligned}
$$

As the technology from the agricultural firm follows a constant returns to scale Cobb-Douglas, the firm will have zero profit in equilibrium. Revenue is divided between remuneration of labor and land: $\alpha_{r}$ is the share of revenue destined to labor, and $1-\alpha_{r}$ is 
the share destined to land. Hence, expenditures on labor are:

$$
\begin{aligned}
w_{k r t} N_{k r t} & =\alpha_{r} \sum_{m=1}^{M} p_{k r t}^{m}\left(\eta_{k r t}^{m}\right)^{-\frac{1}{\theta}} A_{k r t}^{m}\left(N_{k r t}^{m}\right)^{\alpha_{r}}\left(L_{k r t}^{m}\right)^{1-\alpha_{r}} \\
& =\alpha_{r} \sum_{m=1}^{M} p_{k r t}^{m}\left(\eta_{k r t}^{m}\right)^{-\frac{1}{\theta}} A_{k r t}^{m}\left(\eta_{k r t}^{m} N_{k r t}\right)^{\alpha_{r}}\left(\eta_{k r t}^{m} L_{k r t}\right)^{1-\alpha_{r}} \\
& =\alpha_{r}\left(N_{k r t}\right)^{\alpha_{r}}\left(L_{k r t}\right)^{1-\alpha_{r}} \sum_{m=1}^{M} p_{k r t}^{m}\left(\eta_{k r t}^{m}\right)^{1-\frac{1}{\theta}} A_{k r t}^{m},
\end{aligned}
$$

where we used the fact that, following our hypothesis on technology, share of labor employed in the production of a crop is the same as the share of land. The agricultural wage follows the equation:

$$
w_{k r t}=\alpha_{r}\left(\frac{L_{k r t}}{N_{k r t}}\right)^{1-\alpha_{r}} \sum_{m=1}^{M} p_{k r t}^{m}\left(\eta_{k r t}^{m}\right)^{1-\frac{1}{\theta}} A_{k r t}^{m} .
$$




\section{Appendix B - Data}

Figure B.1 - Brazil's Macro-regions

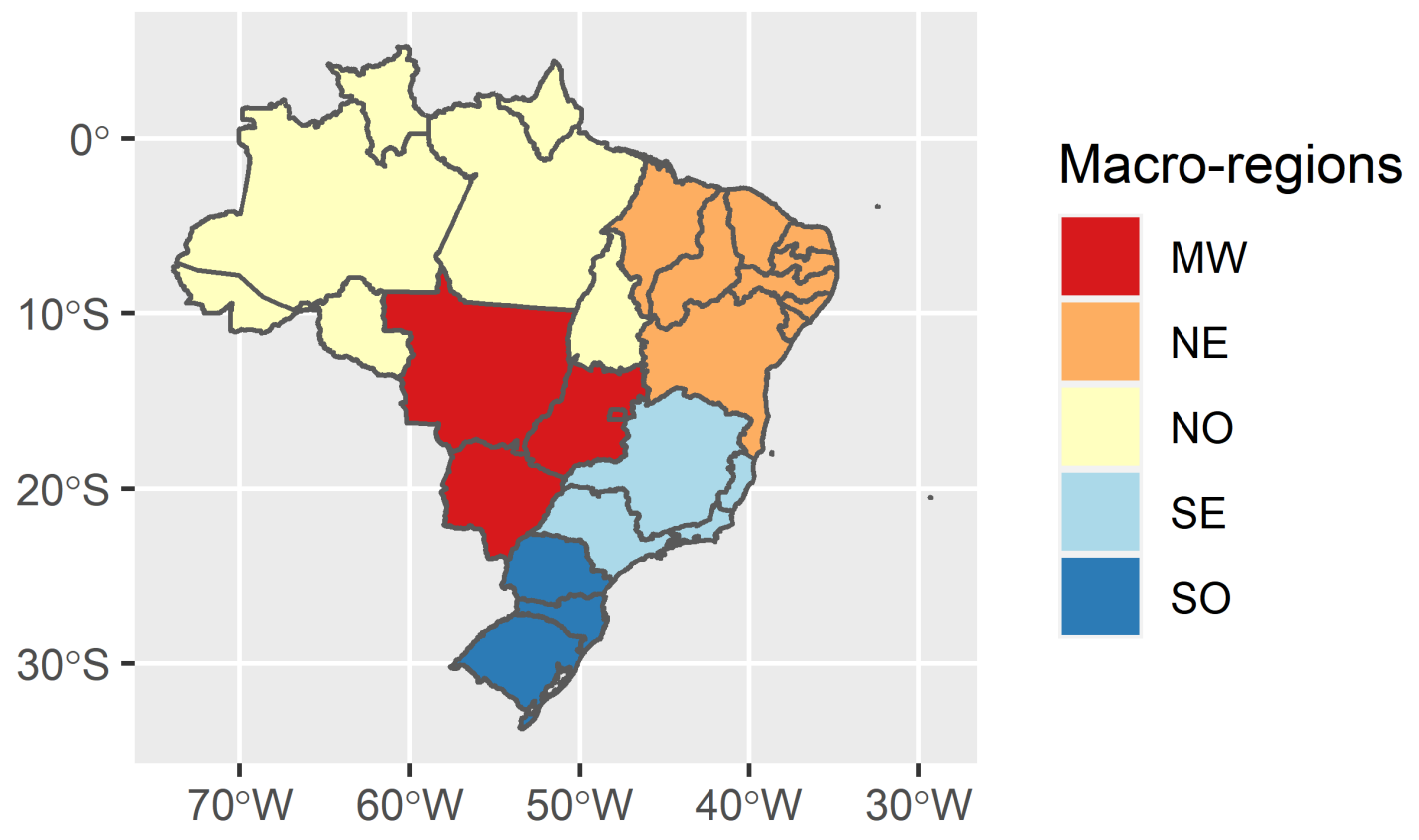

Note: 26 Brazilian states and 1 Federal District grouped into five macro-regions. Macroregions are: Midwest (MW), Northeast (NE), North (NO), Southeast (SE), and South (SO). Data source: IBGE 
Table B.1 - GAEZ Crop Productivities Distribution (t/ha)

\begin{tabular}{lccccccc}
\hline \hline Statistic & Mean & St. Dev. & Min & Pctl(25) & Median & Pctl(75) & Max \\
\hline Banana & 3.443 & 2.108 & 0.000 & 1.736 & 3.926 & 5.280 & 6.399 \\
Cassava & 5.870 & 1.991 & 0.000 & 5.433 & 6.732 & 7.177 & 7.859 \\
Coconut & 0.542 & 0.844 & 0.000 & 0.000 & 0.000 & 1.009 & 2.820 \\
Coffee & 1.023 & 0.592 & 0.000 & 0.538 & 1.265 & 1.460 & 1.830 \\
Cotton & 0.412 & 0.179 & 0.000 & 0.305 & 0.406 & 0.535 & 0.793 \\
Cowpea & 1.609 & 0.347 & 0.205 & 1.454 & 1.677 & 1.868 & 2.082 \\
Dryland Rice & 2.556 & 1.081 & 0.000 & 2.366 & 2.985 & 3.307 & 3.556 \\
Groundnut & 1.773 & 0.565 & 0.002 & 1.552 & 2.020 & 2.173 & 2.397 \\
Maize & 5.440 & 1.470 & 0.721 & 4.119 & 5.591 & 6.701 & 9.043 \\
Onion & 5.535 & 1.349 & 0.503 & 4.820 & 5.718 & 6.616 & 8.648 \\
Phaseoulus Bean & 2.150 & 0.452 & 0.247 & 1.932 & 2.309 & 2.471 & 2.731 \\
Soybean & 2.247 & 0.469 & 0.256 & 2.059 & 2.378 & 2.586 & 2.898 \\
Sugarcane & 5.510 & 2.099 & 0.000 & 4.119 & 6.028 & 7.249 & 8.454 \\
Sunflower & 1.635 & 0.912 & 0.000 & 0.789 & 2.124 & 2.309 & 2.996 \\
Tobacco & 0.682 & 0.188 & 0.000 & 0.600 & 0.701 & 0.813 & 1.031 \\
Tomato & 4.217 & 0.934 & 0.199 & 3.832 & 4.534 & 4.825 & 5.963 \\
Wheat & 1.148 & 1.319 & 0 & 0 & 0.2 & 2.5 & 4 \\
White Potato & 1.945 & 2.282 & 0 & 0 & 0.2 & 4.4 & 7 \\
\hline
\end{tabular}

Note: This table contains the distribution of micro-region average GAEZ crop productivities (t/ha). Crop productivities are set with the baseline climate and intermediate input level assumption and filtered to areas that presented agricultural production in the GAEZ data. First two columns present the mean and standard deviation of the crop productivity values, while the following columns present the quartile distribution of micro-region crop values. Data source: GAEZ. 


\section{Appendix C - Estimation of the Parameters}

Table C.1 - International Trade Exposure Index

\begin{tabular}{lllllr}
\hline \multicolumn{1}{l}{ Crop } & Index & & Crop & Index \\
\hline 1 & Tobacco & 1.83914 & 10 & Rice & 0.13995 \\
2 & Wheat & 1.80686 & 11 & White Potato & 0.13221 \\
3 & Soybean & 1.65704 & 12 & Maize & 0.08254 \\
4 & Coffee & 1.63053 & 13 & Banana & 0.05302 \\
5 & Sugarcane & 1.35450 & 14 & Coconut & 0.04219 \\
6 & Sunflower & 0.99366 & 15 & Tomato & 0.02878 \\
7 & Cotton & 0.97538 & 16 & Cassava & 0.00641 \\
8 & Groundnut & 0.50460 & 17 & Bean & 0.00002 \\
9 & Onion & 0.20990 & & \\
\hline \multicolumn{7}{c}{ Note: $I^{m}$ is a relative crop exposure to interna- }
\end{tabular}

tional trade measure constructed by dividing the crop share of the sum of exports and imports by the crop share revenue of agricultural production.

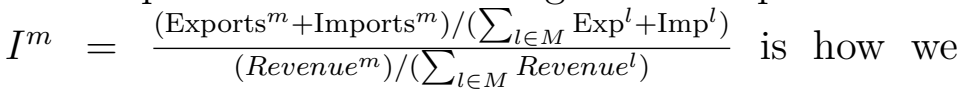
calculate the index. Data source: Agrostat 2005, PAM 2005 .

Table C.2 - Land Share Elasticity: First Stage

Dependent variable

$I^{m} \log$ Distance to Port

$\log \mathrm{Amk}$

Obs.

Kleibergen-Paap Wald rk F stat.

$$
\begin{gathered}
P_{k}^{m} A_{k}^{m} \\
(1) \\
\mathrm{b} / \mathrm{se} \\
-0.0554^{* * *} \\
(0.0103) \\
0.567^{* * *} \\
(0.0271) \\
4585
\end{gathered}
$$

${ }^{*} \mathrm{p}<0.1 ;{ }^{* *} \mathrm{p}<0.05 ;{ }^{* * *} \mathrm{p}<0.01$

Note: Prices are median farmgate prices inside micro-region. Standard errors clustered at the micro-region level. 
Figure C.1 - Model's goodness of fit per crop: land share occupied by crop

\section{Land Share by Crop}
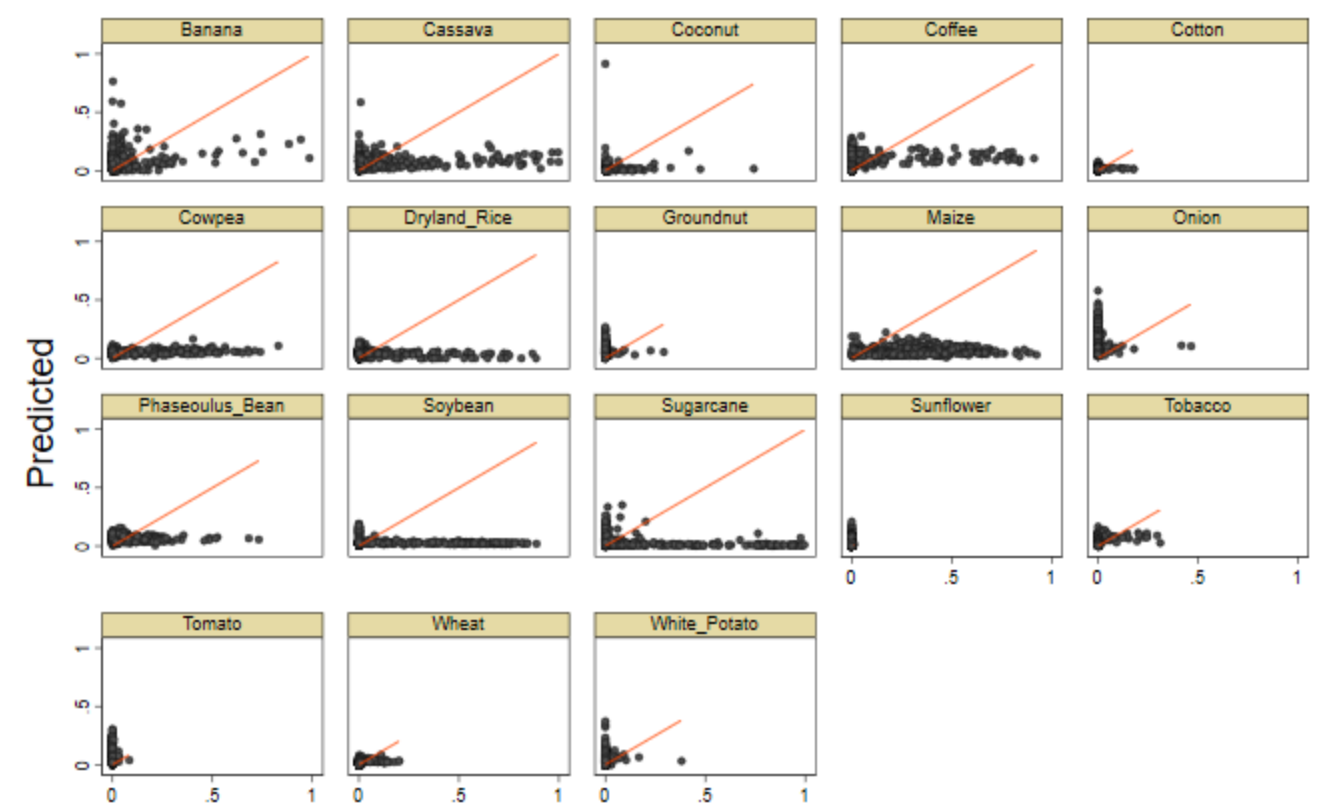

Actual

Note: Each point is a share of agriculture land employed in the production of a crop in a micro-region. Data source: Agricultural Census 2006, GAEZ, Model estimates.

\section{C.1 Alternative Agriculture Production Model with 10 crops}

Table C.3 - Land Share Elasticity

\section{Dependent variable}

$\theta$

Obs.

Kleibergen-Paap Wald rk F stat. 115.9

$$
{ }^{*} \mathrm{p}<0.1 ;{ }^{* *} \mathrm{p}<0.05 ;{ }^{* * *} \mathrm{p}<0.01
$$

Note: Alternative model estimation including only ten crops (Soybean, Maize, Sugarcane, Dryland Rice, Cowpea, Coffee, Phaseoulus Bean, Cassava, Wheat, Cotton). Prices are median farm-gate prices inside micro-region. Standard errors clustered at the micro-region level. 
Table C.4 - Land Share Elasticity: First Stage on Prices

Dependent variable

$$
\eta
$$

(1)

$\mathrm{b} / \mathrm{se}$

$I^{m} \log$ Distance to Port

$-0.149^{* * *}$

$(0.0139)$

$\log A_{k r t}^{m}$

$-0.808^{* * *}$

(0.0489)

Obs.

Kleibergen-Paap Wald rk F stat. 115.9

$$
{ }^{*} \mathrm{p}<0.1 ;{ }^{* *} \mathrm{p}<0.05 ;{ }^{* * *} \mathrm{p}<0.01
$$

Note: Alternative model estimation including only ten crops (Soybean, Maize, Sugarcane, Dryland Rice, Cowpea, Coffee, Phaseoulus Bean, Cassava, Wheat, Cotton). Prices are median farmgate prices inside micro-region. Standard errors clustered at the micro-region level. 
Figure C.2 - Model's goodness of fit (Model with 10 crops): land share occupied by crop

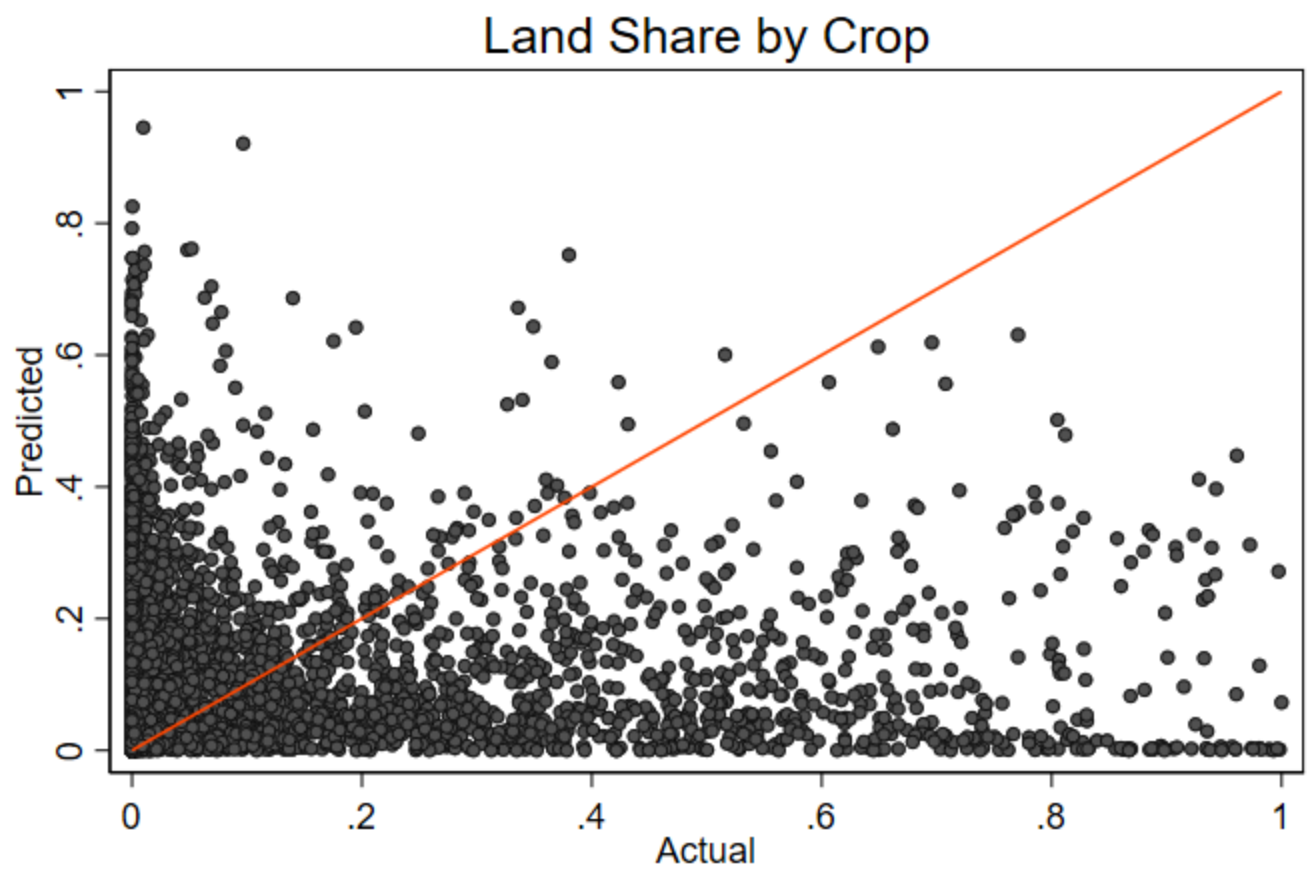

R-squared: 0.0055

Note: Alternative model estimation including only ten crops (Soybean, Maize, Sugarcane, Dryland Rice, Cowpea, Coffee, Phaseoulus Bean, Cassava, Wheat, Cotton). Estimated value for $\theta$ with this selection of crop is 2.079. Each point is a share of agriculture land employed in the production of a crop in a micro-region. Data source: Agricultural Census 2006, GAEZ, Model estimates. 
Figure C.3 - Model's goodness of fit per crop (Model with 10 crops): land share occupied by crop

\section{Land Share by Crop}
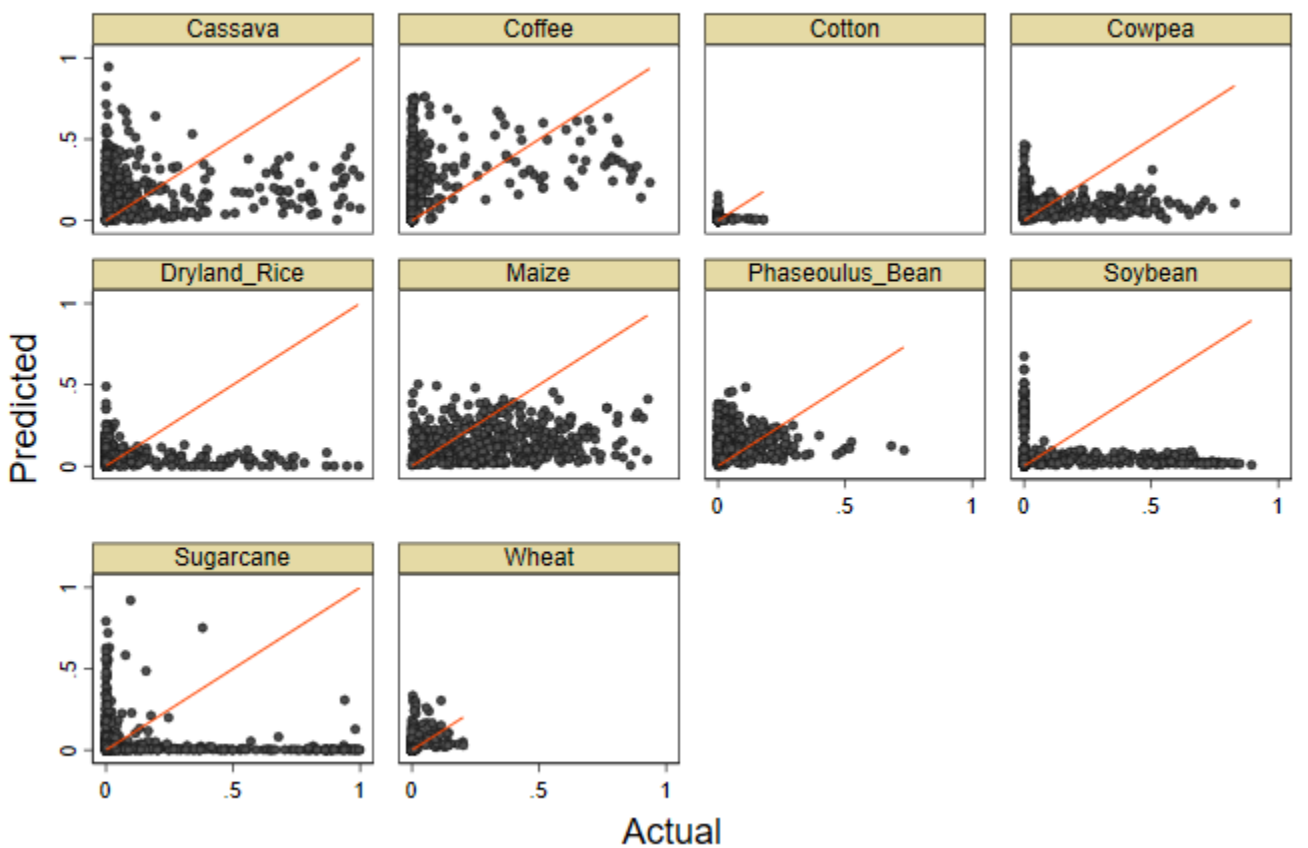

Note: Alternative model estimation including only ten crops (Soybean, Maize, Sugarcane, Dryland Rice, Cowpea, Coffee, Phaseoulus Bean, Cassava, Wheat, Cotton). Estimated value for $\theta$ with this selection of crop is 2.079. Each point is a share of agriculture land employed in the production of a crop in a micro-region. Data source: Agricultural Census 2006, GAEZ, Model estimates. 